University of Tennessee Health Science Center UTHSC Digital Commons

\title{
Patient Perceptions of Quality: The Influence of Value and Beneficence
}

\author{
Rebecca H. Waldon \\ University of Tennessee Health Science Center
}

Follow this and additional works at: https://dc.uthsc.edu/dissertations

Part of the Health Services Administration Commons, Health Services Research Commons, and the Nursing Administration Commons

\section{Recommended Citation}

Waldon, Rebecca H. , "Patient Perceptions of Quality: The Influence of Value and Beneficence" (1994). Theses and Dissertations (ETD). Paper 422. http://dx.doi.org/10.21007/etd.cghs.1994.0425.

This Thesis is brought to you for free and open access by the College of Graduate Health Sciences at UTHSC Digital Commons. It has been accepted for inclusion in Theses and Dissertations (ETD) by an authorized administrator of UTHSC Digital Commons. For more information, please contact jwelch30@uthsc.edu. 


\title{
Patient Perceptions of Quality: The Influence of Value and Beneficence
}

\begin{abstract}
The influence of patient values and patient perception of benefits on patient perceptions of quality have not been extensively investigated, even though patient and provider perceptions of quality have been widely studied. Refocusing quality assessment and improvement to include factors that influence patient perceptions of quality is necessary for humanitarian and economic reasons. The health care patient has certain expectations of health care. These expectations are based on the value the patient places on the services. Value is a predictor of patient-perception of quality. The relative worth of patient goals may also be related to patient perceptions of quality. If so, providers need to consider this when giving care and assessing quality. This study was a secondary analysis of a study by Larrabee, "Hospital Patients' and Nurses' Perception of Quality". The sample consisted of 199 patients. The purpose of this study was to examine the relationships between quality and value as relative worth and quality and beneficence from the patient's perspective. There were four key findings. First, a close relationship was found between patient-perceived quality and value and patient-perceived quality and beneficence. These findings supported the proposition that value and beneficence are related to quality. Second, this study provided partial support for the proposition that value as relative worth is related to quality. This finding identifies the need for further research into the qualitative nature of patient goals and their different rankings. Third, patients appeared to value all their goals equally even when pain relief was one of their goals. However, when pain relief was identified as goal one, the achievement of this goal was related to increased patientperceived quality. Finally, a strongly positive relationship was found among all three patient goals. This indicated that patient goals may be interrelated and interdependent on each other, and that the achievement of one leads to the achievement of the others. The implications for nursing include nurses having patients identify their own health goals. By validating the worth of the patient's goals, by acknowledging them and assisting in their achievement, the nurse will demonstrate beneficence. As the patient perceives benefits from care, their perceptions of quality should increase. In conclusion, the findings in this study suggest that assisting patients in meeting all their health goals is an important strategy for improving patient outcomes and patient satisfaction. It also may help an agency maintain market share, since satisfied patients are more likely to return for future care.
\end{abstract}

\section{Document Type}

Thesis

Degree Name

Master of Science (MS)

Program

Nursing

Research Advisor

June H. Larrabee, Ph. D., R. N.

Keywords

Nursing, Patient perception, Quality of care

\section{Subject Categories}

Health Services Administration | Health Services Research | Medicine and Health Sciences | Nursing | Nursing Administration

This thesis is available at UTHSC Digital Commons: https://dc.uthsc.edu/dissertations/422 
Patient Perceptions of Quality: The Influence of Value and Beneficence

A Thesis Presented to the Faculty

$$
\text { of }
$$

The University of Tennessee, Memphis

In Partial Fulfillment

of the Requirements for the Degree

Master of Science in Nursing

from the University of Tennessee

by

Rebecca H. Waldon

June, 1994 
Dedication

This work is dedicated to:

James L. and Martha Holliday, my parents,

H. Phillip Waldon, Jr., my husband,

and

John Jamieson Waldon, my son 


\section{Acknowledgements}

I gratefully acknowledge my thesis committee who advised and supported me while enabling me to complete this work:

June H. Larrabee, Ph. D., R. N., my chair, who was influential in my interest in quality and who became my mentor in the different aspects of quality. Dr. Larrabee, exhibited determinism, guidance, patience and humor while challenging me to meet the full potential of this study. She was generous in her time and knowledge and of this I am very appreciative.

Margaret Hartig, Ph. D., R. N., my committee member, who made herself available and offered valued insight. She provided beneficial advice on clarification of my subject and findings.

I also gratefully acknowledge the following people who were instrumental in the successful completion of this work and degree.

Natalie Person, my statistician, worked with the data base to perform the correct analyses and interpretations. She was proficient and gracious in all of our interactions.

Jan Tidwell, my sister and friend, who cheered me on. Her assistance with my family allowed me to focus on this work. Marci Sweeney, my friend, who offered encouragement when I became disheartened and helped so much with my son. 


\section{ABSTRACT}

The influence of patient values and patient perception of benefits on patient perceptions of quality have not been extensively investigated, even though patient and provider perceptions of quality have been widely studied. Refocusing quality assessment and improvement to include factors that infuence patient perceptions of quality is necessary for humanitarian and economic reasons.

The health care patient has certain expectations of health care. These expectations are based on the value the patient places on the services. Value is a predictor of patient-perception of quality. The relative worth of patient goals may also be related to patient perceptions of quality. If so, providers need to consider this when giving care and assessing quality.

This study was a secondary analysis of a study by Larrabee, "Hospital Patients' and Nurses' Perception of Quality". The sample consisted of 199 patients. The purpose of this study was to examine the relationships between quality and value as relative worth and quality and beneficence from the patient's perspective.

There were four key findings. First, a close relationship was found between patient-perceived quality and value and patientperceived quality and beneficence. These findings supported the proposition that value and beneficence are related to quality. Second, this study provided partial support for the proposition that value as relative worth is related to quality. This finding identifies the need for further research into the qualitative nature of patient goals and their different rankings. Third, patients appeared to value all their goals equally even when pain relief was one of their goals. However, when pain relief was identified as goal one, the achievement of this goal was related to increased patient-perceived quality. Finally, a strongly positive relationship was found among all three patient goals. This indicated that patient goals may be interrelated and interdependent on each other, and that the achievement of one leads to the achievement of the others.

The implications for nursing include nurses having patients identify their own health goals. By validating the worth of the patient's goals, by acknowledging them and assisting in their achievement, the nurse will demonstrate beneficence. As the 
patient perceives benefits from care, their perceptions of quality should increase.

In conclusion, the findings in this study suggest that assisting patients in meeting all their health goals is an important strategy for improving patient outcomes and patient satisfaction. It also may help an agency maintain market share, since satisfied patients are more likely to return for future care. 


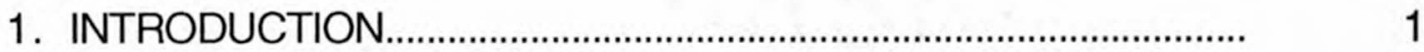

Conceptual Framework..........................................................

Relevance to Nursing.............................................................

Research Questions.............................................................. 9

Definitions of Concepts..................................................... 16

Operational Definitions..................................................... 18

Assumptions................................................................. 19

Limitations.......................................................................... 21

2. REVIEW OF LITERATURE...................................................... 25

Quality....................................................................... 25

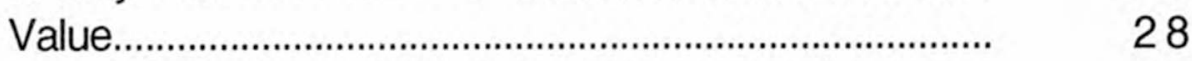

Beneficence................................................................... 33

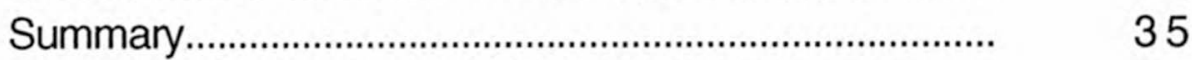

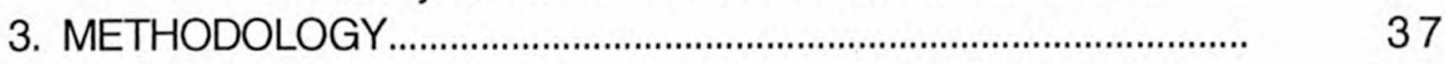

Research Design ................................................................... 37

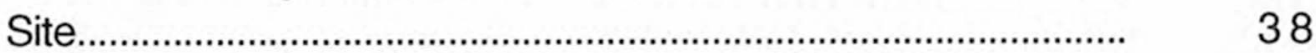

Sample............................................................................... 38

Measurement of Patient Variables................................... 39

Procedure............................................................................. 40

Protection of Human Subjects............................................ 42

Analysis of Research Questions....................................... 42

4. RESULTS........................................................................... 44

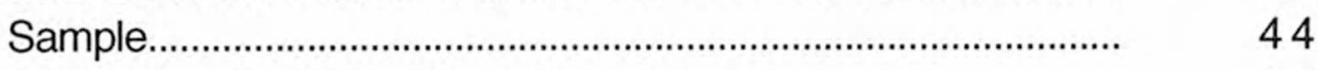

Descriptive Statistics.................................................... 44

Analysis of Research Questions...................................... 47

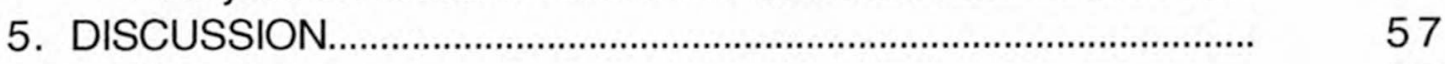

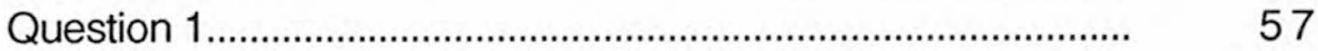

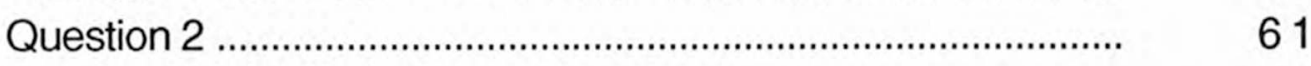

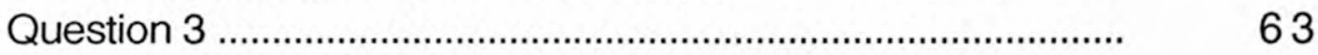

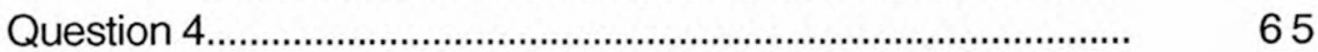

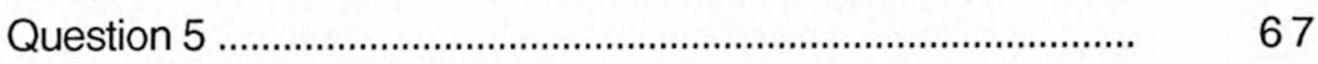

Question 6 ...........................................................................

Strengths and Limitations..................................................

Theoretical Framework........................................... 71

Generalizability.................................................... 72

Measurements............................................................... 
Future Research Questions............................................ $\quad 74$

Conclusion ..........................................................................

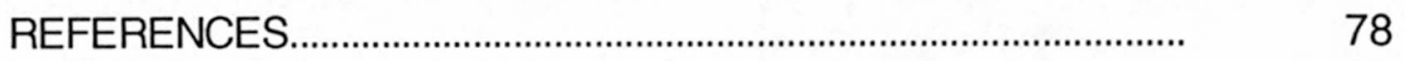

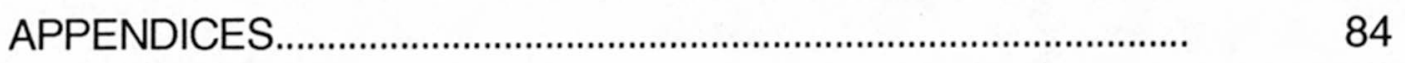

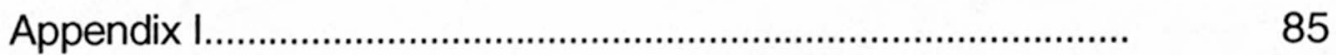

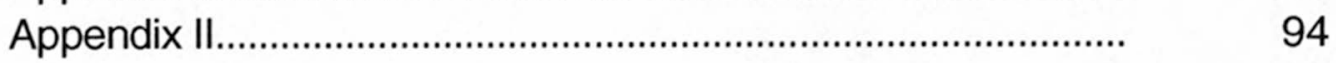

Appendix III..................................................................... 101

Appendix IV ............................................................................. 103

Appendix V...................................................................... 105

VITA 


\section{LIST OF TABLES}

TABLE

PAGE

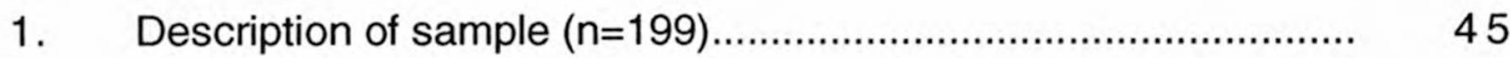

2. Descriptive statistics for patient quality variables, patient value variables and patient beneficence variables.

3. The relationship between patient quality and value variables measured by estimated Spearman's correlations.

4. Test for homogeneity among correlation coefficients for patient-perceived quality scores (PQUALG \& PQUALT) and patient goal scores (PGOAL1, PGOAL2, \& PGOAL3).

5. The relationship between patient quality and patient beneficence variables measured by estimated Spearman's correlations

6. Test for homogeneity among correlation coefficients estimating the relationships between each quality variable (PQUALG \& PQUALT) and patient goal for pain score (PGOALP) and scores for the other patient goals (PGOALO)

7. The relationship between patient quality variables and goals for pain ranked number 1 , number 2 , or number 3 measured by estimated Spearman's correlations.....

8. The relationship between patient value variables measured by estimated Spearman's correlations 


\section{LIST OF FIGURES}

FIGURE

PAGE

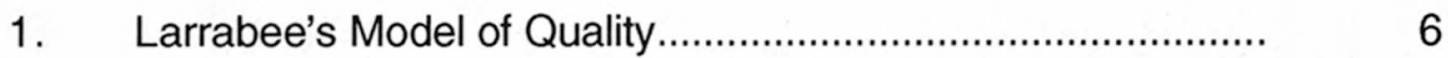

2. Model for Investigation........................................................ 11

3. PQUALG/PQUALT-PGOAL1, PGOAL2, PGOAL3

(Questions 1 \& 2) ................................................................... 12

4. PQUALG/PQUALT-PGOALP, PGOALO

(Questions 3 \& 4) ...................................................................... 14

5. PQUALG/PQUALT-PGOALP1, PGOALP2, PGOALP3

(Question 5)............................................................................ 15

6. PGOAL1, PGOAL2, PGOAL3

(Question 6). 


\section{CHAPTER 1}

\section{INTRODUCTION}

The influence of patient values and patient benefits on patient perceptions of quality has not been extensively investigated, even though patient and provider perceptions of quality have been widely studied (Vuori, 1982; Larrabee, 1992). Quality has been predominantly provider-defined (Steffen, 1988; Larrabee, 1992) and quality assessment has been predominately provider-focused (Lalonde, 1988; Larrabee, 1992). Refocusing quality assessment and improvement to include patient definitions of quality and factors that influence patient perceptions of quality is necessary for humanitarian and economic reasons. The humanitarian reason is that providers have a social obligation to promote well-being or provide benefits to recipients of health care (Larrabee, 1992). The economic reasons are that patients with high perceptions of quality are less likely to sue (Lalonde, 1988) and are more likely to recommend and return for services (Linn, 1975; Raatikainen, 1991) than those with Iow perceptions of quality. With health care reform imminent, 
budget constraints, and increased competition for consumers, providers must aggressively pursue quality improvements that influence patient perceptions of quality.

Patient perceptions of quality have largely been viewed as outcome indicators of quality (Donabedian, 1982; Larrabee, 1992), suggesting patients are passive recipients of care. However, Larrabee (1992) proposed that patients and their families be treated as partners in health care to better meet their expectations for benefits of health care and for better achievement of providers' outcomes for patients. Larrabee (1992) proposed that beneficience, "defined as actual or potential capability for producing good and promoting well being," was related to quality. She demonstrated that beneficence, measured as low pain score, was a predictor of patient-perceived quality. Therefore, the benefits achieved through health care influence patients' perception of quality. Beck (1993) failed to support this theoretical relationship; however, measurement issues may have contributed to her findings. No other studies were located which have investigated the relationship 
between patient perceptions of health care benefits and their perceptions of quality.

Larrabee (1992) also theorized that value influences perceptions of quality and demonstrated that value as intrinsic worth, measured as patient goal achievement, was a predictor of patient-perceived quality. Recipients of health care have certain expectations of health care quality, including achievement of their own healthrelated goals. If those expectations differ from those of the providers, there will doubtless be a discrepancy between the recipients of the health care and the providers as to whether quality care was provided (Steffen, 1988).

Goals provide a purpose for an action or an aim. Patient's goals are intended to be included in outcome measurements of quality, but too often, measurements are taken using the health provider's own goals (Buck, 1974; Steffen, 1988; Larrabee, 1992). Consumers have increasingly sophisticated qualitative criteria concerning the care they receive. These criteria may emphasize aspects that the professionals deem unimportant or even irrelevant for high quality. This is natural because providers and consumers have different implicit and explicit objectives that are not necessarily 
symmetrical or reciprocal (Buck, 1974). Providers should find out what patient's goals are, because goal incongruence may adversely effect goal achievement. Awareness of and planning for patient goals should have a positive impact on the quality and cost effectiveness of health care (Larrabee, 1992).

There is a growing awareness of the importance of customer satisfaction as a determinant of high quality care. Patient satisfaction has been studied widely in hospitals, physician offices, and clinics (Linn, 1975). But, as Larrabee (1992) found, the predominant categories studied are interpersonal care, provision of information, communication, living arrangements, or the amenities. Larrabee (1992) located no instruments which evaluate the influence on patient satisfaction of patient expectations about health status on discharge. Therefore, quality, as a concept based on the meeting of patients' expectations or goals has not been investigated thoroughly.

Further, Larrabee (1992) proposed that value as relative worth also influences perceptions of quality. Patients may not value each of their own goals equally so that one may be relatively more important than another. To date, no studies have investigated the 
proposed relationship between value as relative worth and patient perceptions of quality. Therefore, the purpose of this study is to investigate the relationship between quality and value as relative worth and between quality and beneficence from the patient's perspective.

\section{Conceptual Framework}

The conceptual framework for this study is Larrabee's Model of Quality, a new wholistic model of quality (see Figure 1). This model is a synthesis of Aristotle's ethical philosophy, concepts from quality assurance literature, and concepts from a linguistic analysis (Larrabee, 1992). In Larrabee's model, quality encompasses at least four interrelated concepts: value, beneficence, prudence, and justice. This study will focus on the concepts of quality, value and beneficence. Larrabee postulates in her model that the quality of care delivered will influence beneficence. Benefits achieved will, in turn, influence patient perceptions of quality, depending on the value of the benefits to the patient. Larrabee further postulates that value is a possible intervening, or a weighting concept, between 


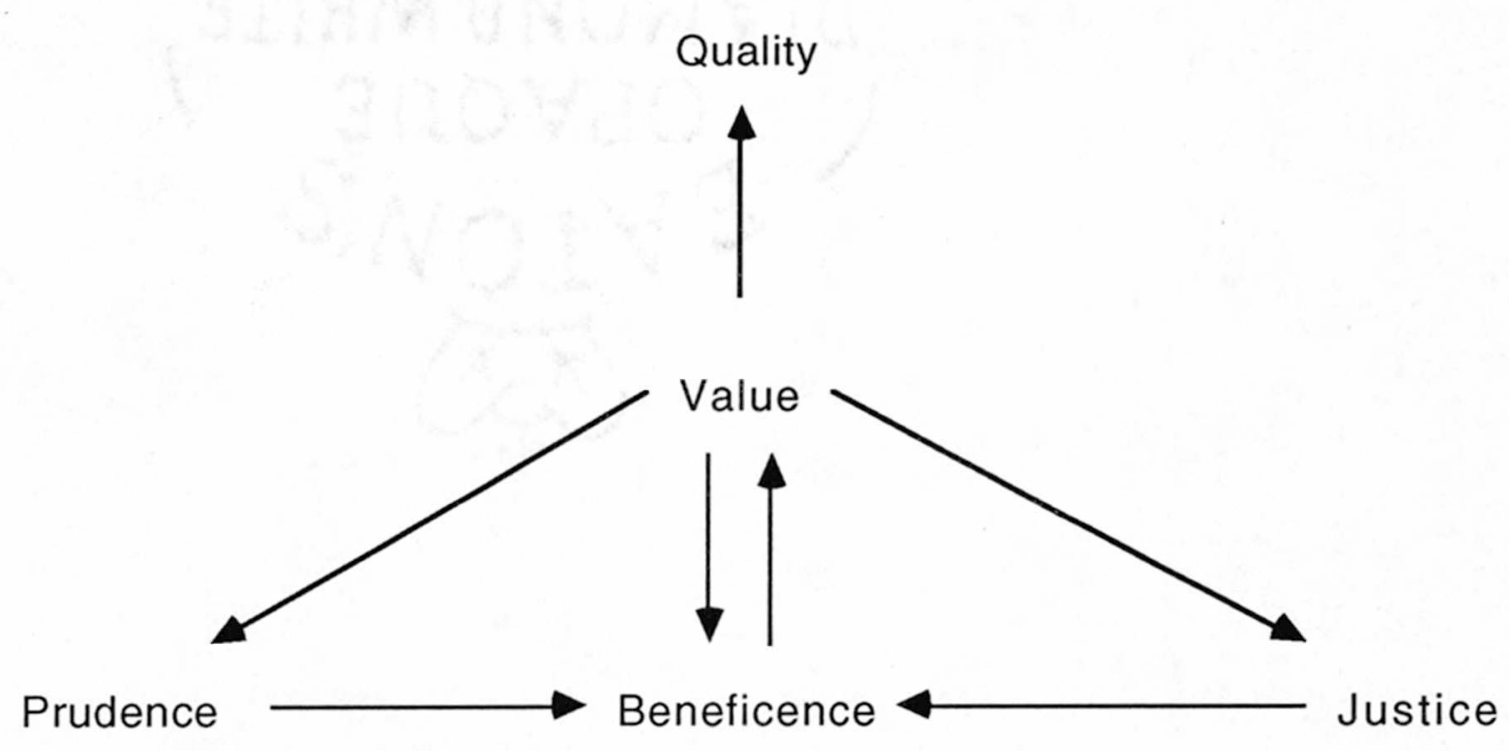

Figure 1. Larrabee's model of quality. 
quality and the remaining concepts of this model. This study will test the postulation: value is an intervening link between quality and beneficence.

\section{Relevance to Nursing}

What something means to someone is intrinsic in their own belief system, based on past experiences, culture and their values or mores. The question of meaning has fundamentally to do with how humans interpret their encounter with their physical and social world (Hefner, 1978). Many nurses have little specialized training in the use of symbolic connotations and communication is likely to be further hampered by differences between the patient's viewpoint and the nurse's. This problem stems from social differences in the role, status and general background of nurse and patient. Such factors are intrinsic conditions of nurse-patient interaction rather than means which the bedside nurse can manipulate in caring for the patient (Wooldridge, 1983).

Ida Orlando, a nursing theorist, states that learning how to understand what is happening between herself and the patient is the 
central core of the nurse's practice and comprises the basic framework for the help given to patients. Her nursing theory emphasizes the reciprocal relationship between patient and nurse. Both are affected by what the other says or does (Marriner-Tomey, 1989). Many patients who have been responsible for taking an active part in their own care while outside of the hospital are cast in the conflicting role of being passive during hospitalization and illness. Many difficulties between staff and patients and many aspects of patient behavior attributed to their medical condition may be symptomatic of any human in a role-conflict situation, rather than peculiar to hospitalized patients (Wooldridge, 1983).

Identification of goals by the patient using his own words, as in Larrabee's study, enables nurses to clarify with less chance of misinterpretation, the values and expectations the patient has and allows the patient to express his expectations, thus validating his worth. Larrabee (1992), states that nurses could plan care that is more congruent with patient perceptions if they knew how important different patient goals are to patients. The ranking as to the degree of importance these goals are to patients can only enhance the nurse-patient relationship. The meeting of these goals, identified by 
patients and recognized by nurses, empowers patients and increases their perception of quality. The achievement of the patient-set goals also permits nurses to abide by one of the strongest principles of nursing, beneficence, the duty to do good. Beneficence is a basic, underlying ethical principle inherent in the profession of nursing (Uustal, 1985).

\section{Research Questions}

The specific purpose of this study is to examine the relationships between 1) quality (PQUALG \& PQUALT) and value (PGOAL1, PGOAL2, \& PGOAL3) and the differences in those relationships and 2) quality (PQUALG \& PQUALT) and beneficence (PGOAL, PGOALP \& PGOALO) and the differences in those relationships. This study will begin the process of defining value as an intervening variable between beneficence and quality by performing a secondary analysis of data collected by Larrabee (1992) in her research, 'Hospital Patients' and Nurses' Perceptions of Quality". 
The data analyzed for this study will be the scores for achievement of an aggregate of patient goals (PGOAL), patient goal for pain (PGOALP), and patient goals other than pain (PGOALO). The patient-perceived quality total score (PQUALT) and patientperceived quality global score (PQUALG) will be used. Finally, the degree of importance of patients' goals (PGOAL1, PGOAL2, \& PGOAL3) will be used (see Figure 2). This study will investigate the research questions:

1) Is there a relationship between patient-perceived quality (PQUALG \& PQUALT) and patient goal score 1 (PGOAL1), patient goal score 2 (PGOAL2) and patient goal score 3 (PGOAL3)? (see Figure 3).

2) Are there differences in the relationships between: patientperceived quality (PQUALG \& PQUALT) with patient goal 1 (PGOAL1), patient-perceived quality (PQUALG \&PQUALT) with patient goal 2 (PGOAL2), and patient-perceived quality (PQUALG \&PQUALT) with patient goal 3 (PGOAL3)? (see Figure 3) 


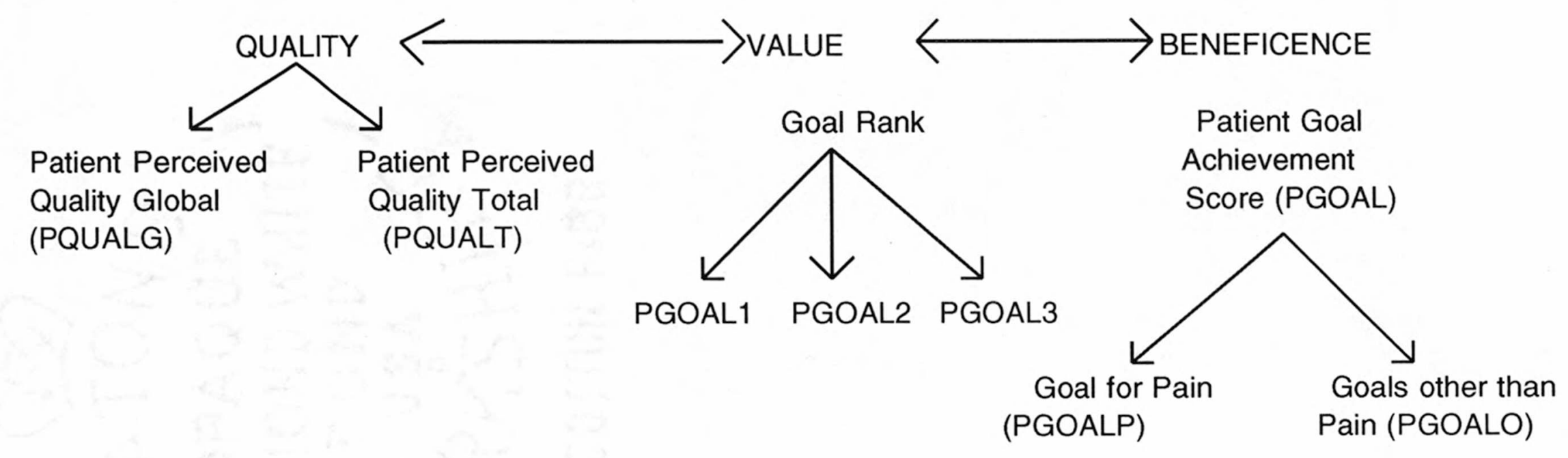

Figure 2. Model for investigation.

Modified from 'Hospital Patients' and Nurses' Perceptions of Quality” by J.H. Larrabee, 1992, doctoral dissertation, The University of Tennessee, Memphis. 


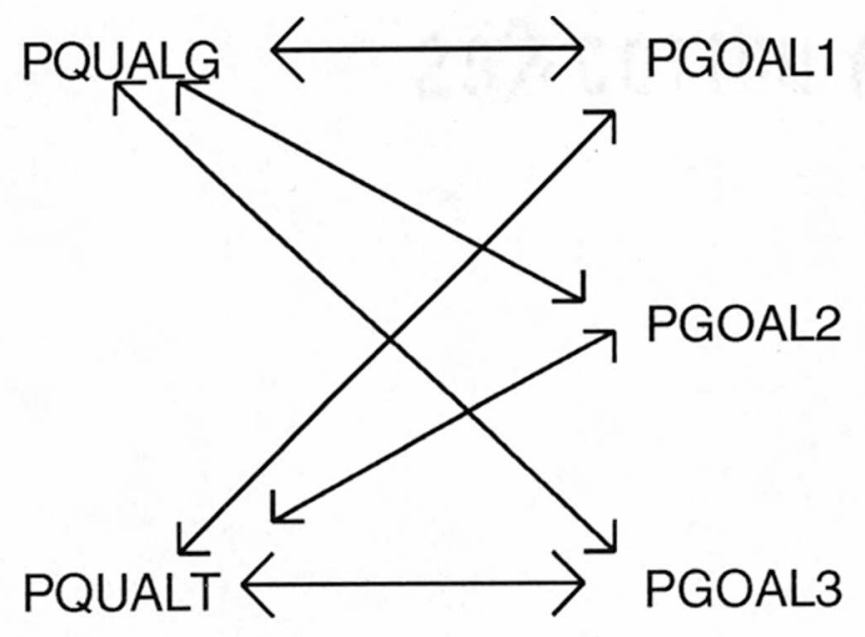

Figure 3. (Questions $1 \& 2$ ). 
3) Is there a relationship between patient-perceived quality scores (PQUALG and PQUALT) and the goal for pain (PGOALP) and between patient-perceived quality scores (PQUALG and PQUALT) and the scores for the patients' other goals? (PGOALO)? (see Figure 4)

4) Are there differences in the relationship between patientperceived quality scores (PQUALG and PQUALT) and goal for pain scores (PGOALP) and in the relationship between patient-perceived quality and the scores for patients' other goals (PGOALO)? (see Figure 4).

5) Is there a relationship between patient-perceived quality scores (PQUALG and PQUALT) and the goal for pain as first most important goal (PGOALP1), PQUALG and PQUALT and goal for pain as the second most important goal (PGOALP2), and PQUALG and PQUALT and goal for pain as the third most important goal for hospitalization (PGOALP3)? (see Figure 5) 

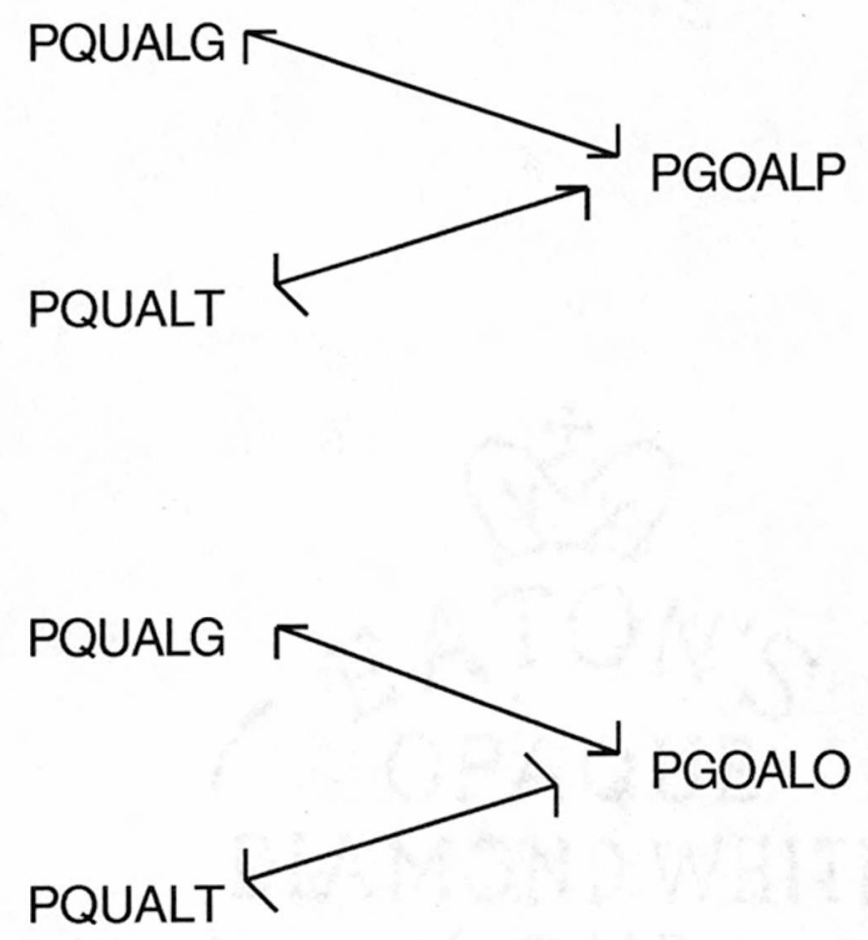

Figure 4. (Questions 3 \& 4). 


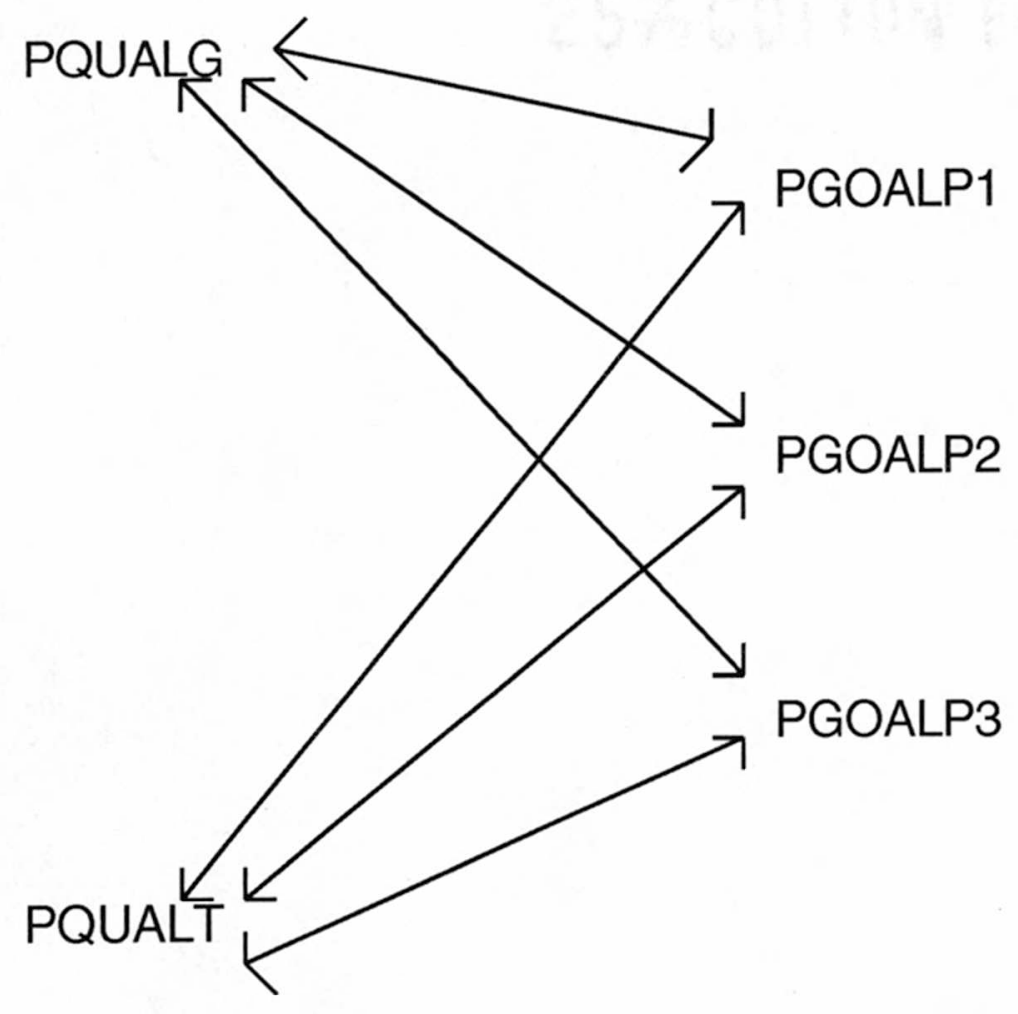

Figure 5. (Question 5). 
6) Are there relationships among patient goal 1 score (PGOAL1), patient goal score 2 (PGOAL2), and patient goal score 3 (PGOAL3)? (see Figure 6)

\section{Definitions of Concepts}

Quality. Quality for the purpose of this study is defined as "the presence of socially-acceptable, desired attributes within the multifaceted wholistic experience of being and doing. "Patient goal achievement is significantly correlated with patient-perceived quality" (Larrabee, 1992).

Value. Value for the purpose of this study is defined as "relative worth, utility or importance" (Larrabee, 1992). The weight or worth of this concept is explicitly linked with quality by Donabedian (1968) and Steffen (1988)

Beneficence. Beneficence for the purpose of this study is defined as "actual or potential capability for (a) producing good and (b) promoting well being". Beneficence encompasses harmlessness (Larrabee, 1992). Support for beneficence being integral in a 


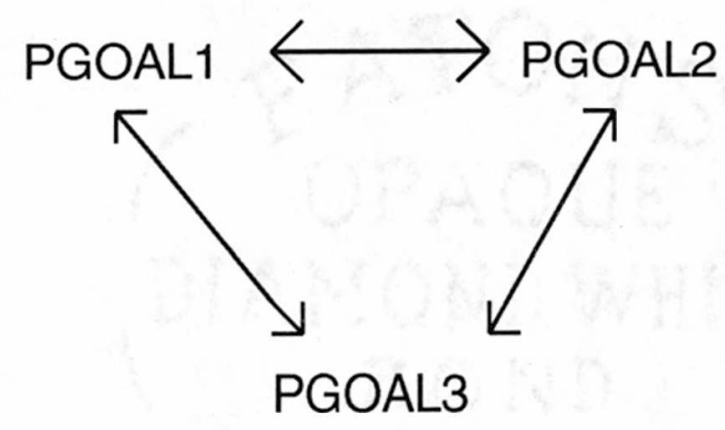

Figure 6. (Question 6). 
construct of quality is found throughout the literature related to quality (Donabedian, 1968; Larrabee,1992).

\section{Operational Definitions}

Quality is operationalized by patient-perceived quality (PQUALG/PQUALT). In Larrabee's study (1992) patient-perceived quality was measured by a one-item $100 \mathrm{~mm}$ visual analogue scale (VAS) (global score) and by a modified version of the "Nursing and Daily Care Subscale" of the "Patients' Judgement of Hospital Quality Questionnaire" (total score) (Larrabee, 1992).

Value is operationalized by patient goal ranked as to degree of importance (PGOAL1, PGOAL2, PGOAL3) . In Larrabee's study, PGOAL operationalized "value as intrinsic worth". Patient goal achievement (PGOAL) was measured as the average of three scores on VASs indicating patient perception of achievement of a maximum of three goals for hospitalization (Larrabee, 1992). The higher the score, the greater the patient's estimation of goal achievement. Patients defined their own goals. These three goals were classified as goal 1, goal 2, and goal 3. In this study, the classification of the goal, or the rank, operationalizes value as relative worth. The 
higher the score, the greater the patient's estimation of goal achievement.

Beneficence is operationalized as achievement of goal for pain (PGOALP) and goals other than pain (PGOALO). Goal achievement for pain (PGOALP) was the score on a $100 \mathrm{~mm}$ VAS for achievement for pain-related goals set by patients (Larrabee,1992). The score for achievement of goals other than pain (PGOALO) was obtained by subtracting the goal achievement for pain score from the PGOAL composite score and determining the average of the remaining scores [PGOAL - PGOALP divided by $n$ ] (Larrabee, 1992).

\section{Assumptions}

There are several assumptions intrinsic to this study. A major assumption is that Larrabee's model of quality and its underlying assumptions are valid. In addition, the researcher makes the following assumptions:

1) Relative importance or worth of goals of hospitalization influences patient-perceived quality. The higher the relative worth of a goal, the stronger correlation between that goal's achievement and patient-perceived quality. 
2) The patient-perceived quality total score and patientperceived quality global score accurately estimate the patient perceptions of the quality of nursing care they received during hospitalization.

3) The patient goal achievement score accurately estimates patient perceptions of the extent to which their goals for hospitalization were achieved.

4) the questions used on the interviews would measure the study concepts intended and not other phenomena.

5) The use of the VAS (visual analogue scale) as a scoring format for the patient questions is appropriate for the dynamic, subjective nature of the study concepts. It has demonstrated more sensitivity to changes in a measured phenomenon than other scales, and it yields ratio level data.

6) The ranking of goals was in accordance with the importance or value of these goals to the patient. 


\section{Limitations}

1) First, the demographic characteristics of this sample was comparable to the hospital population in race and age, being predominately black and young. The mean age of this sample was 39 years, $51 \%$ of the sample were male, $82 \%$ were black, and approximately $20.7 \%$ had education beyond high school. Thus, the generalizability of this study was limited to adults, predominantly young black males, with education limited to high school with acute care needs, hospitalized on two general medical-surgical nursing units. The results of this study may be generalized only to other metropolitan, tertiary, safety-net hospitals with similar patient populations. Although the National Association of Public Hospitals does not collect demographic data for safety net hospital patient, comparisons can be made on payor source. Private insurance represented a low percentage of payor source for the sample $(14.6 \%)$ and for other safety net hospitals (15\%). Also, a high percentage of patients in the sample $(42.4 \%)$ and in other safety net hospitals $(30 \%)$ had no third party payor. Thus, in terms of financial resources 
for health care, the sample was comparable to other safety net hospitals (Larrabee, 1992).

2) The validity of the patient quality variables was threatened in this study because there is no standardized instrument for measuring the study concepts as defined by Larrabee (1992), and the psychometric properties of Larrabee's instrument were not established. However, construct validity was established for measurement of patient-perceived quality because PQUALT was developed from the "Nursing and Daily Care Subscale", a standardized subscale of the "Patients' Judgements of Hospital Quality Questionnaire”. (Larrabee,1992). Also, examining testretest reliability of an instrument when measuring a non-stable phenomenon is inappropriate, unless done with a very short time interval, which in itself is a potential bias (Larrabee, 1992).

Two measurement issues were identified by Larrabee, scale response bias, relative to patient-perceived quality global and patient-perceived quality total, and "ceiling effect". First, scale response bias may have occurred with patient-perceived quality total since all eight of the items had the identical scale.

Second, "ceiling effect" was evident in the extreme negative 
skew of patient-perceived quality global and total. The first possible explanation offered by Larrabee (1992) is that "ceiling effect" may represent a tendency of this population to rate patientperceived quality well above average. The second possible explanation offered by Larrabee for this "ceiling effect" was that the right hand anchor "very good", on the visual analogue scales did not indicate superlative to this patient population. Larrabee (1992) stated that this anchor violates the principle that the anchors suggest the complete absence or the complete presence of the phenomenon being measured. During scale development, Larrabee (1992), the investigator, designed the patient interviews to have a 6th grade reading level. After consultation with expert nurses at the study hospital, "very good" was selected as a more appropriate right hand anchor for this sample than "excellent". Yet, during patient interviews, the researcher heard patients with less than a 10th grade education using superlative words like "excellent", "outstanding", and "extremely good". The researcher, therefore, concluded that many patients may have marked the visual analogue scale on the extreme right hand side because they thought the care was better than how they define "very good". 
Patient goal achievement also demonstrated the "ceiling effect" as evident in the negative skew. Larrabee offered a plausible explanation for this skew as a tendency of this patient population to rate patient goal achievement above average. The scale configuration did not allow patients to distinguish between degrees of excellence in goal achievement.

3) The use of the VAS (visual analogue scale) has not been previously tested in a predominantly black population. However, subjects in Larrabee's study did not experience difficulty using this response scale. 


\section{CHAPTER 2}

\section{REVIEW OF LITERATURE}

This literature review is organized to address each of the concepts of quality, value and beneficence, sequentially. Discussion will address pertinent theoretical literature and then pertinent research literature for each of these three concepts.

\section{Quality}

The review of the literature reveals that a definition of quality can mean different things to different disciplines, institutions or groups (Buck, 1974; Steffen, 1988; Larrabee, 1992). Patient satisfaction as a measure of quality has also been explored and reported in the literature (Linn, 1975; Raatikainen, 1991; von Essen \& Sjoden, 1992; Laferriere, 1993). Donabedian (1982) defines medical care quality in terms of outcomes associated with the care received. Specifically, the highest quality of care is that which yields the greatest expected improvement in health status, health 
being defined broadly to include physical, physiological, and psychological dimensions.

Larrabee (1992) states that in past studies of quality analysis, the lack of consistency of concepts has been a major limitation in defining quality. She expresses the thought that some of the elements of the construct of quality have been easier to define and to measure than others. Specifically, it has been easier to define and measure the structure and process (provider) elements of care quality than outcomes (recipient, or patient). She reports that structure and process approaches to quality assessment have predominated the literature. Larrabee's quality model (figure 1) is wholistic and more abstract than other quality models in an attempt to bridge gaps in previously existing models. In part, this is an effort to make patient/family views integral in a quality model. Patient satisfaction can serve as an outcome indicator of the quality of nursing care received (Laferriere, 1993). In spite of the fact that many social scientists and most physicians have questioned the validity and significance of evaluations patients make of their medical experiences, several research studies have demonstrated their importance (Linn, 1975; Becker \& Maiman, 1975). 
It has been noted that changing attitudes and satisfactions with medical care are not only worthwhile goals in themselves, but have some very practical consequences. One of these consequences reported by Francis, Korsch, and Morris is that it has been shown that the greater the patient satisfaction the more likely he is to follow the doctor's orders (cited in Linn, 1975).

Also, with the advent of patients as consumers, they are becoming increasingly powerful to the extent that their needs and satisfactions can no longer be neglected by either physician "providers" or medical scientists (Linn, 1975). Raatikainen (1991) points out that researchers, Speedling and Rose, argue that patient satisfaction is an insufficient measure of the quality of the patientcare provider relationship. The interaction should also encourage patients to take an active role in their care.

Larrabee (1992) states that the majority of the literature either explicitly or implicitly incorporates value in the definition of quality, substantially supporting its inclusion in a model of quality. She demonstrated the relationship between value and quality postulated by her model of quality, because patient quality was correlated with both patient goal achievement and nurse goal 
achievement and because patient goal achievement was a predictor of both measures of patient quality (Larrabee, 1992).

\section{$\underline{\text { Value }}$}

Value as relative worth, as perceived by the patient, has thus far been measured in studies using patient satisfaction surveys as a guide to what they valued. Value can also be linked to patient goals, as determined by their perspectives of relative worth. To aid in determining what affects what patients deem important or of worth, two psychological theories will be explored, the locus of control and the related health belief model. Larrabee (1992) noted that knowledge is needed about the relationship between recipients' satisfaction with the amenities, interpersonal care, or technical care and either their estimation of the value of the care or the providers' estimation of the quality of care.

The literature also reveals that patient goals and health care provider goals may not be congruent or the same (Buck, 1974;

Steffen, 1988). Since values are linked with goals, or what is of importance to the patient, this can be a determining factor in patient satisfaction and perceptions of quality. 
Steffen (1988) asserts that patients' goals do not flow just from the nature of the disease, but also from the patient as a human being. Their previous experiences, when added to their individual values, beliefs and culture contribute to their goals and expectations of health care (Steffen, 1988; Ali, et al. 1993).

Two theories may aid in understanding goal setting and its relative importance or value to patients. These are the locus of control and the health belief model. The health locus of control, based on Rotter's social learning theory, was developed to measure the degree to which people perceive themselves as having control over their own health (Schlenk, 1984). Rotter, a psychologist, described the social learning theory as the potential for a behavior to occur in any specific psychological situation as a function of the expectancy that the behavior will lead to a particular reinforcement from that situation and the value of that reinforcement (Rotter, 1975). The health locus of control scale measures the degree to which people perceive themselves as having control over their own health. A belief of external control exists when reinforcement is seen as following some action, yet not contingent on that action, and 
therefore beyond personal control. Internal control occurs when the individual believes that his actions do determine the outcome of his situation.

The health belief model based on the value-expectancy theories of social psychology and initially developed in the 1950's, explained health related behavior at the level of the individual decision maker (Blair, 1993). McAllister and Farquhar (1992) state that the two components of the health belief model are: 1) the value placed by an individual on a particular outcome; and 2) the individual's estimate of the likelihood that a given action will result in that outcome.

This considers the subjective perceptions of the individual. It refers to the "the lay belief that health either is, or is not, determined by the individual's actions and behavior" (McAllister \& Farquhar, 1992).

The health belief model has been recently expanded by the addition of the variable of self efficacy (Blair, 1993). Self efficacy predicts and explains individuals' health behavior. According to this theory developed by Rosenstock (1988), two types of expectancies exert powerful influences on behavior: outcome expectancy and self efficacy. Outcome expectancy is the conviction that particular 
behaviors will lead to particular outcomes. Self efficacy expectancy is the belief that one can successfully execute the behavior required to produce the outcomes. Underlying these expectancies is the individual's perceptions of these expectancies that influence behavior (Salazar, 1991).

These two theories, locus of control and health belief model, have been used in the past, mainly to predict or aid in compliance by patients with their health care regimens. However, they may also be applied generally to patient values or how much worth they place on their expectations or goals and how much they feel these goals are under their control. The concepts of these theories, a person's belief in control of a situation-health belief model, internal locus of control- or belief in little control of a situation-external locus of control, form a basis for identifying patients' goals. The identification of these goals will enable health professionals, especially nursing personnel, to assist the patients in meeting their goals, thereby improving their perception of quality. The ranking of these goals should show the degree of importance placed by the patient on these goals. 
Avedis Donabedian MD, MPH, called the "Dean of Quality Assessment" (Steffen, 1988), states that an individual's health can be influenced by the medical care system, genetics, the environment and the patients behavior (1968). A basically similar but even larger notion of the determinants of health care is that the level of health of the people is only to a very modest degree the results of health care (Blum, 1974). Therefore, patients as individuals with individual goals or expectations of relative worth should be recognized as equal colleagues in the accomplishment of those goals by health care professionals, including nursing personnel.

Until recently, patients were expected to be the passive recipients of nursing care. This passive role has been changing, and nurses are now being actively encouraged to promote the inclusion of patients in decision-making (Biley, 1992). Steffen (1988) urges that goals be set by the patient with the help of his physician and stated explicitly in the chart in order to be available for peer review of quality assessment. In this way quality of care will be improved if the patient and medical personnel goals are mutually understood and pursued (Steffen, 1988) 


\section{Beneficence}

Beneficence is defined as actual or potential capability for: (a) producing good and (b) promoting well-being. Beneficence encompasses harmlessness (Larrabee, 1992). Larrabee (1992) points out that numerous authors have implied benefits to recipients when discussing both preventing undesired outcomes, and achieving desired outcomes. Lalonde (1988) states that quality assurance typically embodies the assurance that the care delivered is necessary, appropriate, safe, and effective, all synonymous with beneficence. Donabedian (cited in Steffen, 1988) is quoted as saying, "the degree of quality is...the extent to which the care provided is expected to achieve the most favorable balance of risks and benefits". Many research studies focus on improving patient outcomes which are intended to be beneficial.

Beck (1993) found a positive relationship between patient goal achievement and diminished pain which is how she operationalized beneficence. It was demonstrated that beneficence, measured as low pain score, was a predictor of patient-perceived quality (Beck, 1993). However, Beck's study (1993) failed to support the 
theoretical relationship between patient-perceived quality and beneficence, although measurement issues may have contributed to her findings. Donabedian (1982) designed a model which defined medical care quality in terms of outcomes, measured as the expected improvements in health status attributable to care. Therefore, beneficence has extensive support for being included within the construct of quality and is the most fundamental concept according to Larrabee (1992).

Caring, perceived by the patient, can be seen as a dimension of beneficence. Tanner, Brenner, Chesla, and Gordon (1993) propose that knowing the patient is essential to patients feeling cared for and about. They cite a study of patients' experiences in caring, wherein it was found that patients place at the top of their list of caring acts, not being "just another case", but rather that care was personalized, and thus not routine (Tanner et al. 1993). von Essen and Sjoden (1993) express that it is important to strengthen the empirical foundation concerning what patients and staff regard as important caring behaviors before any fruitful theory of what makes patients feel cared for can be developed. They found in their study of psychiatric patients that staff and patients state different 
opinions with respect to treatment goals, the importance of various aspects of the treatment, the functioning of patients, and the quality of services. Another implication pointed out was that staff produced education programs, intended care improvements, or evaluation instruments do not necessarily cover those aspects of care that patients perceive as most important (von Essen \& Sjoden, 1993) These studies support the need for identification of patients' goals and their degree of importance to the patient. If patients are to have a real say in their care, nurses must change their attitudes and learn to share decision making in a real and meaningful way (Richards \& Lambert, 1987).

\section{Summary}

Larrabee (1992) states the limited scope and inconsistency of concepts have produced fragmented views of quality and indicate that there are gaps inherent in the current conceptualizations. She points out that prior to her model, existing models could not be used as a framework for examining the influence on health care outcomes of recipient expectations and behaviors. Larrabee's quality model can be used as this framework. Published findings and theories 
support the incorporation of value as relative worth from the patient's perspective as important to the patient's aims or goals. The achievement of these goals has been shown to increase the patient's perception of quality and satisfaction (Larrabee, 1992). Consumers are demanding the right to actively participate in informed decision making regarding the health and nursing care they receive. This nursing care must become patient-centered and outcome-oriented (Laferriere, 1993). By identifying the influence relative worth or value has on patients' perceptions of quality, providers' care can become more patient-centered and outcomeoriented. The literature supports the premise that providers must have means of identifying goals and the relative worth of these goals to the patient, in order to aid patients in meeting goals or accepting that goals may not be met, thus practicing beneficence. 


\section{CHAPTER 3}

\section{METHODOLOGY}

\section{Research Design}

This study, a secondary data analysis of Larrabee's data (1992), tested the relationships among quality, value, and beneficence in Larrabee's model of quality (Larrabee, 1992). In the original study, patient data were collected at two points in time. Patients were interviewed within 24 hours of admission so that patient's goals for hospitalization could be identified for later use in measuring patient goal achievement (see Appendix I). Patients were interviewed a second time, within $24-48$ hours of discharge, to obtain data about patient perceived quality and goal achievement (see Appendix II). In the initial interview patients were asked to identify their first goal, second goal and third goal for hospitalization. In this way, the patients' value or relative worth of these goals was established. 


\section{Site}

The site for the original study was a 455-bed urban teaching hospital with a public mission located in the Mid South. It provides health care for the majority of uninsured and underinsured persons in Shelby County (Larrabee, 1992). The patient population at the study hospital is predominately black (76.5\%) with $64 \%$ females and $76.6 \%$ being 35 or younger.

\section{Sample}

Larrabee's original sample included 199 patients on two medical surgical units in the study hospital, who exhibited the inclusion criteria and agreed to participate. The inclusion criteria were as follows: 1) consent to participate in the study; 2) ability to communicate in English; 3) sufficient vision to mark or point to a location on the visual analog scale (VAS) used to score the questions; 4) age 18 or older; 5) direct admission to one of the two study units; and 6) not imprisoned. 
The sample's findings are generalizable to other metropolitan, safety net hospitals with similar patient populations. These hospitals provide health care for to the nation's uninsured and under-insured persons (Larrabee, 1992).

\section{Measurement of Patient Variables}

Patient-perceived quality (PQUALG, PQUALT). Patient-perceived quality, in the original study (Larrabee, 1992), was measured by a $100 \mathrm{~mm}$ VAS (global scale) and by a modified version of the "Nursing and Daily Care Subscale" of the "Patients' Judgments of Quality Questionnaire" (total score) containing eight questions the responses to which were obtained during the exit interview. These questions were modified from a valid and reliable instrument, "The Patients Judgment of Hospital Quality Questionnaire“ (PJHQ) by Rubin, Ware, Nelson, and Hays (1991). The questions were modified to allow for educational level of the subjects, which was anticipated by Larrabee to be lower than Rubin's et al. sample. The original PQUALG and PQUALT scores were used in this study (Larrabee, 1992). 
Patient goal achievement (PGOAL, PGOALP and PGOALO). Patient goal achievement (PGOAL) was measured by Larrabee in the original study (1992) as the average of three scores on $100 \mathrm{~mm}$ VASs indicating patient perception of achievement of a maximum of three goals for hospitalization. Patients defined their own goals during the initial interview (Larrabee, 1992). Data for those patients with a goal of pain relief were used as the measure of patient goal achievement for pain (PGOALP) and data for those patients with a goal other than pain relief was used as a measure of goal achievement other than pain (PGOALO).

Goal Rank (PGOAL1, PGOAL2, and PGOAL3). Goal rank was identified in the original study by Larrabee (1992) as the patient's first, second and third hope or goal for hospitalization in the initial interview. Achievement of those goals was measured using a $100 \mathrm{~mm}$ Vas scale (PGOAL) on the exit interview.

\section{Procedure}

The original data were collected over an eighteen week period. The initial interview required approximately 10 minutes and the exit interview required approximately 15 minutes. The interview was 
conducted by the investigator (Larrabee, 1992). The investigator read the questions to all patients and in the initial interview wrote the patient's response as to his goals for hospitalization and their order of importance. Within 24-48 hours of discharge, the exit interview was conducted by the investigator. In this interview, the investigator read each question and asked the patient to respond by drawing a line at right angles through the VAS. When the patients were unable to hold the pencil but could otherwise indicate the location for their response, the investigator marked the patients' response. Patient data from both interviews were entered into an EXCELTM spreadsheet, stored on diskettes, and later, transferred to a file in the investigator's account on the mainframe at the University of Tennessee for analysis.

In the present study, the original data were used to extract a score for patient goal achievement for PGOAL1, PGOAL2, and PGOAL3, which were the goals patients reported as being their first, second or third most important goals for hospitalization. All patients had one goal, 189 had two goals, and 113 patients had three goals. From the original data file, scores for PGOALP \& PGOALO were extracted for each patient. Also, goal achievement scores 
were extracted for pain ranked number 1 (PGOALP1; $n=30$ ), pain ranked number 2 (PGOALP2; $n=55$ ) and goal for pain ranked number 3 (PGOALP3; $n=26$ ).

\section{Protection of Human Subjects}

Institutional Review Board (IRB) approval was obtained before the start of the original study. An additional IRB approval was obtained prior to this study for examination of the original data for a different purpose. No consent form was used for this secondary analysis of data, but materials were kept in strict confidence and confidentiality maintained.

\section{Analysis of Research Questions}

All original data analyses were completed using the Statistical Analysis System (SAS) software, version six. SAS is available for use on the VAX cluster, which is located in the Biomedical Information Transfer (BIT) center at the University of Tennessee, Memphis (Larrabee, 1992). The descriptive analyses, including mean, standard deviation, and frequency of the sample and each theoretical variable were performed. Quantatative statistics were used to 
identify differences in relationships between goal measures of importance and patient-perceived quality. These were performed using the Statistical Package for the Social Sciences (SPSS/PC+) (Nie, Hull, Jenkins, Steinbrenner, Bent, 1975) available at the University of Memphis. For research questions 1, 3, 5, and 6, Spearman's correlation was performed because the data were categorical but not normally distributed. For research questions 2 and 4 , the z-test for homogeneity among $2+$ correlations was used to determine if there were differences in correlation coefficients (Sokol \& Rohlf, 1981). This test was calculated with a handheld calculator. 


\section{CHAPTER 4}

\section{RESULTS}

\section{Sample}

The sample $(n=199)$ included 107 men and 92 women (Larrabee, 1992) (see Table 1). Their mean age was 39 years with a mean education level of 11 years. The majority of them were black $(85 \%)$, $13.6 \%$ were white and $55.3 \%$ were single. The religious preference of the sample was primarily protestant $(88.4 \%)$.

\section{Descriptive Statistics}

Descriptive statistics for the patient quality variables (PQUALG and PQUALT), patient value variables (PGOAL1, PGOAL2, PGOAL3), and patient beneficence variables (PGOAL, PGOALP, PGOALO) are displayed in Table 2. All were negatively skewed. 
Table 1

Description of sample ( $\mathrm{n}=199$ ).

\begin{tabular}{|c|c|c|c|c|c|}
\hline Variable & Mean (SD) & Median & Range & $\mathrm{n}$ & Percent \\
\hline \multicolumn{6}{|l|}{ Gender } \\
\hline Male & & & & 107 & $53.8 \%$ \\
\hline Female & & & & 92 & $46.2 \%$ \\
\hline \multicolumn{6}{|l|}{ Race } \\
\hline Black & & & & 170 & $85.4 \%$ \\
\hline White & & & & 27 & $13.6 \%$ \\
\hline Other & & & & 2 & $1.0 \%$ \\
\hline \multicolumn{6}{|l|}{ Marital Status } \\
\hline Single & & & & 110 & $55.3 \%$ \\
\hline Married & & & & 56 & $28.1 \%$ \\
\hline Widowed & & & & 18 & $9.0 \%$ \\
\hline Separated & & & & 15 & $7.5 \%$ \\
\hline \multicolumn{6}{|l|}{ Religion } \\
\hline Protestant & & & & 176 & $88.4 \%$ \\
\hline Catholic & & & & 4 & $2.0 \%$ \\
\hline Muslim & & & & 1 & $0.5 \%$ \\
\hline None & & & & 18 & $9.0 \%$ \\
\hline \multicolumn{6}{|l|}{ Education } \\
\hline Less than high school & & & & 92 & $46.5 \%$ \\
\hline High School graduate & & & & 65 & $32.8 \%$ \\
\hline More than high school & & & & 41 & $20.7 \%$ \\
\hline Education in Years & $10.7(3.2)$ & 12 & $0-17$ & 198 & \\
\hline Age & $39.3(15.6)$ & 37 & $18-88$ & 199 & \\
\hline
\end{tabular}


Table 2

Descriptive Statistics for Patient Quality Variables. Patient Value Variables. and Patient Beneficence Variables.

\begin{tabular}{lrll}
\hline Variable & $\mathrm{n}$ & Mean & (SD) \\
\hline Patient Quality Variables & & & \\
Patient-perceived quality global & 199 & 78.88 & 22.72 \\
Patient-perceived quality total & 197 & 79.36 & 20.79 \\
& & & \\
a $\quad 199$ & 71.17 & 26.80 \\
Patient Value Variables & 189 & 63.99 & 31.90 \\
Patient goal score 1 & 113 & 71.48 & 29.63 \\
Patient goal score 2 & & & \\
Patient goal score 3 & 110 & 66.25 & 32.20 \\
Patient Beneficence Variables & 197 & 69.04 & 24.65 \\
Patient goal for pain score & 30 & 71.23 & 29.38 \\
Patient score for other goals & 55 & 62.98 & 31.62 \\
Patient goal for pain as goal one & & & \\
Patient goal for pain as goal two & & & \\
Patient goal for pain as goal three & 26 & 67.57 & 36.47 \\
\hline
\end{tabular}

Patient variables based on $100 \mathrm{~mm}$ visual analogue scale. 


\section{Analysis of Research Questions}

Question1: Is there a relationship between patientperceived quality (PQUALG \& PQUALT) and patient goal 1 score (PGOAL1), patient goal 2 score (PGOAL2), and patient goal score 3 (PGOAL3)?

Significant relationships were shown between patient-perceived quality (PQUALG \& PQUALT) and patient goal 1 score (PGOAL1) and between patient-perceived quality (PQUALG \&PQUALT) and patient goal 3 (see Table 3). Although, there was no relationship between patient-perceived quality global score (PQUALG) and patient goal score 2, there was a strong relationship shown between patientperceived quality total score (PQUALT) and patient goal score 2.

Question 2: Are there differences in the relationships between patient perceived quality (PQUALG \& PQUALT) with patient goal 1 (PGOAL1), patient-perceived quality (PQUALG \& PQUALT) with patient goal 2 (PGOAL2), and patientperceived quality with patient goal 3 (PGOAL3)? 
Table 3

The relationship between patient quality and value variables

measured by estimated Spearman's correlations

Patient quality

variables

$n$

PQUALG

PQUALT

Patient value variables

$\begin{array}{lccc}\begin{array}{l}\text { Patient goal score 1 } \\ \text { (PGOAL1) }\end{array} & 199 & +.13^{*} & +.16^{\star *} \\ \begin{array}{l}\text { Patient goal score } 2 \\ \text { (PGOAL2) }\end{array} & 189 & +.10 & +.17^{\star *} \\ \begin{array}{l}\text { Patient goal score 3 } \\ \text { (PGOAL3) }\end{array} & 113 & +.23^{* *} & +.36^{\star *}\end{array}$

** significant at $p<.05$, two tailed

* significant at $p<.10$, two tailed 
There was a statistical difference in the relationship between PQUALT and patient goal 1 and the relationship between PQUALT and patient goal 3. There was also a statistical difference in the relationship between PQUALT and patient goal 2 and the relationship between PQUALT and patient goal 3 (see Table 4). None of the other relationships demonstrated a statistical difference.

Question 3: Is there a relationship between patientperceived quality (PQUALG \& PQUALT) and the goal for pain score (PGOALP) and patient-perceived quality (PQUALG \& PQUALT) and the scores for the other patient goals (PGOALO)?

First, there was a significant relationship between patientperceived quality global score (PQUALG) and the goal for pain score (PGOALP) (see Table 5). There was also a significant correlation between patient-perceived quality total score (PQUALT) and the goal for pain score (PGOALP). Second, there was no relationship found between patient-perceived quality global score (PQUALG) and the other patient-goals score (PGOALO). However, there was a 
Table 4

Test for homogeneity among correlation coefficients for

patient-perceived quality scores (PQUALG and PQUALT) and patient

goal scores (PGOAL1, PGOAL2, and PGOAL3).

Correlations compared

n $\quad \mathrm{z}$

PQUALG with PGOAL1 vs PQUALG with PGOAL2

$199 / 189 \quad .30$

$$
r=.13^{*}
$$$$
r=.10
$$

PQUALG with PGOAL1 vs PQUALG with PGOAL3

$199 / 113 \quad-.86$

$$
r=. .13^{*}
$$$$
r=.23^{\star *}
$$

PQUALG with PGOAL2 vs PQUALG with PGOAL3

$189 / 113-1.12$

$$
r=.10
$$

$r=.23^{\star *}$

PQUALT with PGOAL1 vs PQUALT with PGOAL2

$197 / 187 \quad .10$

$$
r=.16^{\star *}
$$

$r=.17^{\star *}$

PQUALT with PGOAL1 vs PQUALT with PGOAL3

$197 / 111-1.80^{*}$

$$
r=. .16^{\star \star} \quad r=.36^{\star *}
$$

PQUALT with PGOAL2 vs PQUALT with PGOAL3

$187 / 111-1.71^{*}$

$$
r=.17^{* *}
$$$$
r=.36^{\star *}
$$

** significant at $p<.05$, two-tailed

* significant at $p<.10$, two-tailed 
Table 5

The relationship between patient quality and patient beneficence variables measured by estimated Spearman's correlations.

\begin{tabular}{lllll}
\hline Patient quality variables & $n$ & PQUALG & PQUALT
\end{tabular}

Patient beneficence variables

$\begin{aligned} & \text { Patient goal for pain } \\ & \text { (PGOALP) }\end{aligned}$
$\begin{aligned} & \text { Patient goals other than } \\ & \text { pain (PGOALO) }\end{aligned}$

** significant at $p<.05$, two tailed

* significant at $p<.10$, two tailed 
significant relationship found between patient-perceived quality total score (PQUALT) and the other patient-goals score (PGOALO).

Question 4: Are there differences in the relationship between patient-perceived quality (PQUALG \& PQUALT) and the goal for pain (PGOALP) and in the relationship between patient-perceived quality (PQUALG \& PQUALT) and the goals other than pain (PGOALO)?

There were no differences found between the relationship of patient-perceived quality (PQUALG \& PQUALT) with PGOALP and the relationship of patient-perceived quality (PQUALG \& PQUALT) with PGOALO (see Table 6).

Question 5: Is there a relationship between patientperceived quality (PQUALG \& PQUALT) and goal for pain as the first most important goal (PGOALP1), PQUALG \& PQUALT and goal for pain as the second most important goal (PGOALP2), and PQUALG \& PQUALT and goal for pain as the third most important goal (PGOALP3)? 


\section{Table 6}

Test for homogeneity among correlation coefficients estimating the relationships between each patient quality variable (PQUALG and PQUALT) and patient goal for pain score (PGOALP) and scores for the other patient goals (PGOALO).

PQUALG with PGOALP vs PQUALG with PGOALO

PQUALT with PGOALP vs PQUALT with PGOALO

$$
r=.26^{\star \star} \quad r=.15^{*}
$$

** significant at $p<.05$, two-tailed

* significant at $p<.05$, two-tailed 
There was a strong relationship between the scores for both measures of patient-perceived quality (PQUALG \& PQUALT) and the score for pain as goal 1 (PGOALP1) (see Table 7). However, there was no relationship between either measure of patient-perceived quality (PQUALG \& PQUALT) and the score for pain goal 2 (PGOALP2) or the score for pain goal 3 (PGOALP3).

Question \#6: Are there relationships among patient goal 1 score (PGOAL1), patient goal 2 score (PGOAL2), and patient goal 3 score (PGOAL3)?

There were significant correlations among all three variables:

PGOAL1, PGOAL2, and PGOAL3. (see Table 8). As one goal increased, so did the others. 


\section{Table 7}

The relationship between patient quality variables and goal for pain ranked number 1 , number 2 or number 3 measured by estimated Spearman's correlations.

Patient quality

variables $n$ PQUALG $n$ PQUALT

Patient goal for pain as goal 1 (PGOALP1)

Patient goal for pain as goal 2 (PGOALP2)

Patient goal for pain as goal 3

$26+.05$ $29 t+.62^{* *}$ (PGOALP3)

$55^{\mathrm{t}}+.10$

$54 t+.13$

$30 t+.57^{\star \star} \quad 29 t+.62^{\star *}$

** significant at $p<.05$, two tailed

* significant at $p<.10$, two tailed

$t$ difference in $n$ due to missing data 
Table 8

The relationship between patient value variables measured by

estimated Spearman's correlations.

$\begin{array}{lll}\text { Patient Goals PGOAL1 } & \text { PGOAL2 } & \text { PGOAL3 }\end{array}$

Patient Goals

PGOAL1

$+.35^{\star *}+.36^{\star *}$

PGOAL2

$+.51^{\star *}$

PGOAL3

** significant at $p<.05$, two-tailed

* significant at $p<.10$, two-tailed 


\section{CHAPTER 5}

\section{DISCUSSION}

\section{Question 1}

Is there a relationship between patient-perceived quality (PQUALG \& PQUALT) and patient goal 1 score (PGOAL1), patient goal 2 score (PGOAL2), and patient goal 3 score (PGOAL3)?

There was a significant positive relationship shown between patient-perceived quality score global (PQUALG) and patient goal 1 score (PGOAL1) and patient goal 3 score (PGOAL3). Thus, as the score for goals 1 and 3 increased, so too, did the scores for patientperceived quality global. Patient-perceived quality total (PQUALT) was related to all three patient goals (PGOAL1, PGOAL2, and PGOAL3). These findings support the Larrabee model's hypothesis that value and quality are related (1992). Patient-perceived quality global (PQUALG) was not related to patient goal score 2 (PGOAL2). This may be explained by the fact that the global score was obtained from a one-item question while the total score was determined by a 
composite of eight questions. In Larrabee's study (1992) and in Beck's (1993), PQUALG was highly correlated with PQUALT $(r=.60, p$ $<.05$, Larrabee, 1992) and they were felt to be measuring the same construct. However, the finding that PQUALG is not related to PGOAL2 may indicate that PQUALT is more precise in its measurement of some dimensions of patient-perceived quality. Yet, PQUALG is an appropriate measure of patient-perceived quality when decreased time is a factor in acquiring a patient's participation (Larrabee, 1992).

The first goal may have represented the chief complaint which caused the patient to be hospitalized. Since the chief complaint was important enough to cause hospitalization for the patient, it is therefore, reasonable that this would be important enough to the patient to be identified as the first goal. The correlation of PGOAL1 with both measures of patient-perceived quality supports the proposition that the greater the value, the greater the perception of quality (Larrabee, 1992).

The results indicate that the second most important goal, as identified by the patient, was in some way equally as important as the first goal. For instance, the identification of relief of pain as 
the number 2 goal was evident almost twice as much as the identification of relief of pain as number 1 or number 3 goals by the patients in the study.

Pain, although not being the chief complaint or reason for hospitalization, was an important facet of the patient's problem, and the relief of that pain could be utmost in the patient's mind. Beck (1993) found that there was a positive correlation between patient-perceived quality (PQUALG \& PQUALT) and patient's identification of pain relief as a goal (PGOALP) being met. The lack of relationship between PQUALG and PGOAL2 suggests that PQUALG does not measure patient perception of pain management quality as precisely as PQUALT.

The correlation between patient-perceived quality (PQUALG \& PQUALT) and patient goal 3 score suggests that the third most important goal for hospitalization, as identified by patients in Larrabee's (1992) study, may have been related to more long term goals i. e "go home" and "be able to resume normal activities". The exit interview took place $24-48$ hours prior to discharge, indicating that the immediate problem had been alleviated or controlled. Therefore, the first two goals had possibly been met by the 
hospitalization and were more short-term goals, while the third goal may have been more long term having to do with life goals. The broadness of these third goals, "I'll get well" and "to go home", as opposed to the more specific first and second goals, "stop the bleeding" and "fix the fracture", exemplify patients' general expectations of health care. It follows, that as they were being discharged, their first and second goals had been met, the majority of the time. This, in turn, did increase their perception of quality. These findings support the supposition that without nurses or health care providers knowing the patient's expectations, there may be incongruence between the patient's and the provider's perception of quality (Buck, 1974; Steffen, 1988). Further investigation into the qualitative nature of patient goals ranked differently would aid in determining how patients' value effects patients' perception of beneficence and quality. 


\section{Question 2}

Are there differences in the relationships between patient-perceived quality (PQUALG \&PQUALT) with patient goal 1 (PGOAL1), patient-perceived quality (PQUALG \& PQUALT) with patient goal 2 (PGOAL2), and patientperceived quality (PQUALG \& PQUALT) with patient goal 3 (PGOAL3)?

There were no differences in four of six pairs of relationships. This may indicate that each goal shared equal value, although patients labeled them as first, second, or third. For example, a person with the diagnosis of pneumonia and congestive heart failure had as his first goal "hope my shortness of breath gets better". His second goal was "I get stronger," and his third goal was "the swelling in my legs will go down". These three goals, while different, all relate to important milestones in that patient's progress toward health recovery and they appear interrelated.

However, the finding that there were differences in two of the six pairs of relationships provides partial support for the proposition that value as relative worth is related to quality. 
PGOAL3 had a higher correlation with patient-perceived quality (PQUALG $r=.26$; PQUALT $r=.36, p<.05$ ) than did the other patient goals. Is there something different about PGOAL3? Further investigation into the qualitative nature of patient defined goals is needed to clarify value as relative worth.

The inconclusive nature of the findings pertaining to the relative worth of patient goals suggests, for now, that the achievement of all goals should increase patient satisfaction. The failure to achieve one goal may adversely effect the patients' perception of quality due to a negative outcome (Lalonde, 1988; Laferriere, 1993). By aiding patients in reaching one of their goals, nurses may also be assisting with achievement of other patient goals for hospitalization. Further descriptive studies regarding patient goals ranked in importance would be helpful in understanding patients' goals and the influence of their relative value on patient perceptions of quality. 


\section{Question 3}

Is there a relationship between patient-perceived quality scores (PQUALG \& PQUALT) and the goal for pain score (PGOALP) and patient-perceived quality scores (PQUALG \& PQUALT) and the patients' other goals (PGOALO)?

First, there was a relationship between both measures of patient-perceived quality (PQUALG \& PQUALT) and the goal for pain score (PGOALP). Pain descriptors reported by study participants included pain, discomfort, burning, headache, hurting, aching, and cramping. Pain relief as a goal for nursing is the ultimate in beneficence. Yet, too often, pain management is inadequate (Patterson, 1992; Shade, 1992; Beck, 1993). Pain is a unique, personal experience (Shade, 1992). By recognizing this and involving the patients in participating in achieving this goal, nurses should increase the patients' satisfaction and thus his perceptions of quality. These findings are consistent with those of Raatikainen (1991) and Beck (1993).

Second, there was a positive relationship between patientperceived quality total score (PQUALT) based on an eight-question 
scale and the scores for goals other than pain (PGOALO). This indicates that, as the achievement of goals other than pain increases, the patient's perception of quality also increases. In other words, achievement of health goals other than pain also influenced patient-perceived quality, as measured by the specific questions in the PQUALT scale. This is an expected finding because patient goal achievement was strongly correlated with increased perception of quality by Larrabee (1992) and Beck (1993). This study used the same data set as Larrabee (1992) and Beck (1993) with PGOALO scores being extracted from the original PGOAL scores. The practice of beneficence implies doing good. By aiding these patients in attaining all their health goals, nurses may increase the patients' sense of satisfaction and increase their participation in their care (Raatikainen, 1991).

Finally, there was no relationship shown between patientperceived quality global score (PQUALG) and the score for goals other than pain (PGOALO). PQUALG is based on a one-item scale which may not be a precise measure of all dimensions of patient perceived quality. This item, "Overall, how good was the nursing care you received," was intended as a wholistic measurement of 
patients' own definitions of quality. Further examination of the patients' own definitions of quality and then, comparison with the specific goals patients reported may suggest explanations for the lack of relationship between PQUALG and PGOALO, as well as between PQUALG and PGOAL2.

\section{Question 4}

Are there differences in the relationship between patientperceived quality (PQUALG \& PQUALT) and goal for pain scores (PGOALP) and in the relationship between patientperceived quality (PQUALG \& PQUALT) and the scores for other patient goals (PGOALO)?

There were no significant differences in the relationship between patient-perceived quality (PQUALG \&PQUALT) with the goal achievement scores for pain (PGOALP), and in the relationship between patient-perceived quality (PQUALG \& PQUALT) and the achievement scores for the other patient goals (PGOALO). This suggests that goals other than pain were equally as important to patients as the goal for pain. This finding is unexpected. Pain relief is viewed as one of the most important functions of the health care 
provider (Laborde, 1992; Marvin, 1992; Shade, 1992; Ali, et al., 1993). Patients are expected to express pain, and health care professionals are expected to recognize it and provide interventions (Ali et al., 1993). Continuous education of health professionals and high tech pain management techniques as well as non-pharmacologic means are sought and tried.

This finding indicates that other goals may have the same value to the patient as the goals for pain. However, other goals of patients may not have received the attention that pain relief goals have. Patients' expression of pain can be dramatic and demand immediate attention. This may result from the fact that pain is immediate and contingent on the present.

Although, Beck (1993) states that many patients did not accurately remember the amount of pain over periods of time and tended to underestimate pain intensity on recall. At the exit interview, with discharge imminent, the patients' condition had probably improved. In the original study (Larrabee, 1992), patients may not have valued the relief of pain as highly as they would have had they been asked at a time closer to the actual time of pain relief. 
However, this finding does point out to health care providers the importance of identifying the more subtle patient goals. Patient goals are subjective and individual for that patient. Patient-nurse participation in goal identification and setting will allow the nurse to become aware of these individualized goals.

\section{Question 5}

Is there a relationship between patient-perceived quality scores (PQUALG \& PQUALT) and the goal for pain as the first most important goal (PGOALP1), PQUALG \& PQUALT and goal for pain as the second most important goal (PGOALP2) and PQUALG \& PQUALT and goal for pain as the third most important goal (PGOALP3)?

There was a significant positive relationship shown between patient-perceived quality scores and the goal for pain as the first most important goal identified by patients. This relationship (PQUALG $r=.57$; PQUALT $r=.62, p<.05$ ) was stronger than any of the other relationships found in this study. This suggests that when pain relief was important enough to the patient to be identified as 
the first goal, the achievement of this goal was related to high patient-perceived quality.

There were no relationships found between the patients' perception of quality and their ranking of pain as their second or third goal. This finding suggests that when pain relief is not identified as the first goal, value as relative worth has little relationship with patient-perceived quality. Yet, when goal for pain is the first goal, patients do have a higher perception of quality and value as relative worth appears to be involved.

The most plausible explanation for pain as goal 2 or 3 not being correlated with perception of quality involves measurement issues. Time factors and how goals change over time could have an effect on the patient's sense of achievement of these goals. The priority for the patient could change hourly as symptoms improve or worsen and affect the relative value of different goals. Patients may not have remembered the intensity of non-acute pain, or pain that was not uppermost on their minds on admission. Thus, they may not have accurately determined their score for relief of this pain at the exit interview. However, when goal for pain was ranked the most important, pain intensity may have been memorable enough for the 
patient to perceive its relief as an important element of beneficence.

A further explanation for these findings is measurement imprecision. In the procedure used by Larrabee (1992) in her study, patients were questioned to identify their first, second, and third hope or goal for hospitalization. This method did not request the patients to list three goals and then rank those goals as to their importance. Instead, the response to the first question about goals may have influenced the patients' responses to the second and third questions. This is suggested because qualitatively, the goals appeared to be interrelated. Perhaps, a better way to determine the importance of the goals to patients would be to have them list their goals and then rank them as to their importance. The exception to this is pain relief described as the patients' first goal. This study's findings suggest that when pain is present to the degree that relief is the most important goal, patients will instinctively identify it as number one.

Nurses must recognize that relief of pain identified by the patient as his most important goal is very important to his perception of quality and satisfaction with health care. All avenues 
of effectively managing patients' pain must be pursued. An awareness of changing goals and priorities of patients progressing through hospitalization or a health care system is also important for nurses to understand. This awareness can help nurses adapt to the patients' changing needs.

\section{Question 6}

Are there relationships among patient goal 1 score (PGOAL1), patient goal 2 score (PGOAL2) and patient goal 3 score (PGOAL3)?

There were very strong positive correlations among PGOAL1, PGOAL2 and PGOAL3. As one goal increased so did the others. This suggests that the achievement score of one goal is related to the achievement scores of the other two goals as suggested in the discussion of question two. This finding may be explained in several ways. First, since the exit interview took place prior to discharge, the patient may have been feeling overly positive and may have indicated his achievement of goals in an overly positive way. This may represent "ceiling effect", a tendency of this population to rate 
goal achievement well above average (Larrabee, 1992). Second, these goals are interrelated and difficult for the patient to separate. One patient with diabetes and cellulitis in his foot identified these three goals which are interrelated: "get sugar under control, save my toe and my foot, and get rid of the pain". Since achievement of one of these goals will probably lead to the achievement of the other goals, the patient's outcome will be more positive. This is clinically significant because Larrabee (1992) found that patient goal achievement is a predictor of quality. Nurses and health providers should recognize the potential interrelationship of patient goals and realize that the achievement of one patient goal may have a positive effect on the achievement of other goals.

\section{Strengths and Limitations}

\section{Theoretical Framework}

This study was a secondary data analysis of a patient-focused investigation of quality (Larrabee, 1992). This is in contrast with most quality investigations which are provider-focused and also with patient satisfaction investigations which elicit patient perceptions. Prior to Larrabee's model of quality, existing quality 
models were conceptually limited (Larrabee, 1992). The holistic nature of Larrabee's model of quality ensures that patient and provider perceptions are integral dimensions of the model. This study further supports the concepts of Larrabee's model of quality. The inclusion of patients' identifying goals in their own words decreases misunderstanding between patients and nurses.

\section{Generalizability}

The generalizability of this study is limited to other metropolitan, tertiary, safety-net hospitals with similar patient populations, the majority of which are young, black and male. Private insurance represented a low percentage of payor source for the sample, and for other safety-net hospitals. Also, a high percentage of patients in the sample and in other safety-net hospitals had no third party payor. Thus, in terms of financial resources for health care, the sample was comparable to other safety-net hospital populations (Larrabee, 1992).

The sample was comparable to the hospital population in race and age (Larrabee, 1992). Several features of this sample limit generalizability. The sample included adults with acute care needs 
hospitalized on two medical-surgical units (Larrabee, 1992).

Therefore, the results are not applicable to children, adults with critical care or maternity needs, or patients in outpatient settings, homes or nursing homes.

\section{Measurements}

As in the original study (Larrabee, 1992), several issues threaten the validity of the patient quality and patient value variables of this study. First, no standardized instruments had been developed for measuring patient goal achievement. Therefore, assumptions were made that the questions used would measure the study concepts intended and not other phenomena (Larrabee, 1992).

Second, the patient quality and patient value variables were skewed. This may be due to a tendency of people to rate quality and goal achievement highly. Alternately, it suggests a measurement error, as previously discussed by Larrabee (1992).

Finally, in the present study, there is an additional measurement issue that threatens the validity of the findings for questions 2 and 
5. In the original study patients were asked their first, second, and third goals for hospitalization. Alternately, it is possible that asking patients to rank their health care goals in the order of importance may more precisely measure value as relative worth. Further investigation is needed to clarify this measurement issue.

\section{Future Research Questions}

The findings of this study suggest several questions about patients' expectations of health care and their perception of quality based on those expectations. The following are questions which could be addressed in future research:

1. Is the chief complaint related to the patient's first goal for hospitalization?

2. What does the patient perceive as important caring measures exhibited by health care personnel?

3. Does a person's belief that he can or can not effect his outcome have an influence on his perception of quality?

4. Are patients' goals congruent with nurses' goals?

5. When patients identify goals and then rank them as to their 
importance, is there a difference in their relationships with quality measures?

6. Does a higher perception of quality signify higher patient compliance with medical care?

7. Does patient goal achievement influence the hospital length of stay?

8. Do patients' priorities change over time?

9. Does a person's locus of control influence his goal setting or his perception of goal achievement?

10. Does value as services or goods received, a third definition by Larrabee (1992), influence the patient's perception of quality?

\section{Conclusion}

This study provided several key findings. First, the close relationships between patient-perceived quality and value and between patient-perceived quality and beneficence support the proposition that value and beneficence are related to quality. The clinical implication for nurses is encouragement of patients' active participation in mutual goal setting, while maximizing patient goal achievement. 
Second, value as relative worth was partially supported by slight differences in relationships between quality and ranked patient goals. These findings suggested that there may be qualitative differences regarding ranking goals differently. An implication for nurses is further investigation to determine if there are qualitative differences in ranked goals. Continuously recognizing changing priorities for patients, assessing them, and taking appropriate actions to address them remains a substantial nursing function.

Third, when pain is intense enough to be identified as the most important goal, pain relief is strongly related to patient-perceived quality. Therefore, the pursuit of pain management measures and strategies continues to be essential for nurses.

Finally, the close relationships among patient goals indicate that goals are interdependent and related to each other. Nurses must become aware of the importance of patient goal achievement and the interdependence of goals. Then, they may act as enablers in assisting patients to achieve them. This may allow patients to view nurses as more caring, which may lead to increased patient satisfaction and compliance with health care.

Patients appear to value all goals equally unless their pain is 
intense enough for then to rank pain relief as number one. Patient goal achievement is a predictor of patient-perceived quality (Larrabee, 1992) and patient-perception of quality is a predictor of patient intent to recommend and to return to hospitals (Abramowitz et al, 1987; Meterko \& Rubin, 1990). Therefore, the findings of this study suggest that assisting patients in meeting all their health goals is an important strategy for improving patient outcomes, patient satisfaction, and intent to recommend and return. This strategy, therefore, will assist health care facilities and providers in remaining economically viable in this time of national health care reform. 


\section{REFERENCES}




\section{REFERENCES}

Abramowitz, S., Cote, A., \& Berry, E. (1987). Analyzing patient satisfaction: A multianalytic approach. Quality Review Bulletin, April, 122.

Ali, N., Khalil, H., \& Yousef, W. (1993). A comparison of American and Egyptian Cancer Patients and unmet needs. Cancer Nursing, 16 (3), 193-203.

Beck, K. (1993). Pain and Hospital Patients' Perception of Quality. Unpublished masters thesis, University of Tennessee, Memphis, Tn.

Becker, M. \& Maiman L. (1975). Sociobehavioral Determinants of compliance with Health and Medical Care Recommendations. Medical Care, 13 (1), 11-21.

Biley, F. (1992). Some determinants that effect patient participation in decision-making about nursing care. Journal of Advanced Nursing. 17, 414-421.

Blair, J. (1993). Social Learning Theory. AAOHN Journal, 41 (5), 245-249.

Blum, H. (1974). Evaluating Health Care. Medical Care 12 (9), 9991011.

Buck, C. (1974). A Framework for Good Primary Medical Care- the Measurement and Achievement of Quality. Journal of the Royal College of General Practitioners. 24. 599-604.

Cruikshank, N. (1968). On Assuring Quality in Health. Angeles National Health Forum, 1968, 1.

Donabedian, A. (1968). Promoting Quality through Evaluating the Process of Patient Care. Medical Care $\underline{6}$ (2), 181-201. 
Donabedian, A. , Wheeler, J.R.C. , \& Wyzewianski, L. (1982).

Quality, cost, and health: An integrative model. Medical Care $\underline{20}$ (10), 975-992.

Eachus, P. (1991). Multidimensional health locus of control in nurses. Journal of Advanced Nursing, 16, 165-171.

Fish, John. (1978). Social Justice and the Serviced Society. In W.W. Schroeder \& G. Winter (Eds.), Belief and Ethics (pp. 169-182). Chicago, Illinois: Center for the Scientific Study of Religion.

Francis, V., Korsch, B. \& Morris, M. (1969). Gaps in doctorpatient communication, patients' response to medical advice. New England Journal of Medicine 280 (10), 535-540.

Fuchs, V. (1979). Economics, Health, and Post-Industrial Society. Milbank Memorial Fund Quarterly 57 (2). 153-172.

Hamilton, Jon. (1994, April 18). Hospitals enter bold new era with tougher advertisements. The Commercial Appeal, p. B4.

Hefner, Phillip. (1978). Purpose, Belonging, and Evil: Pivots of Meaning. In W. W. Schroeder \& G. Winter (Eds.), Belief and Ethics (pp. 57-68). Chicago, Illinois: Center for the Scientific Study of Religion.

Kenney, J. (1992). The consumer's views of health. Journal of Advance Nursing. 17, 829-834.

LaBorde, P. (1992). Pain Medications and Management Techniques. Pain Management of the Burn Patient. A Workshop Review. Yardley, Pennsylvania: The Medicine Group, USA. 9-13.

Laferriere, R. (1993). Home Health Care Nursing. Journal of Community Health Nursing. 10 (2), 67-76.

Lalonde, B. (1988). Assuring the Quality of Home Care via the Assessment of Client Outcomes. Caring, 20-24. 
Larrabee, J. (1992). Hospital Patients' and Nurses'

Perceptions of Quality. Unpublished doctoral dissertation, The University of Tennessee, Memphis, Tn.

Linn, L. (1975). Factors Associated with Patient Evaluation of Health Care. In J. B. McKinlay (Ed.), Health Care Consumers. Professionals and Organizations (pp. 171-187). Cambridge, Massachusetts: M.I.T. Press.

Marriner-Tomey, A. (1989). Nursing Theorists and Their Work. (2nd ed.). St. Louis: The C. V. Mosby Company.

Marvin, J. (1992). Pain in the Burn Patients: An Overview. Pain Management in the Burn Patient. A Workshop Review. Yardley, Pennsylvania: The Medicine Group USA, Inc. 4-7.

McAllister G. \& Farquhar M. (1992). Health beliefs: a cultural division? Journal of Advanced Nursing. 17. 1447-1454.

Meterko, M. \& Rubin, H. (1990). Patient judgements of hospital quality: A taxonomy. Medical Care, $\underline{28}$ (9), Supplement, s10-14.

Newmark, J. (1988). Statistics and Probability in Modern Life (4th ed.) Fort Worth: Saunders College Publishing.

Nie, N., Hull, C., Jenkins, J., Steinbrenner, K., Bent, D. (1975). Statistical package for the social sciences (SPSS) (2nd ed.). New York: McGraw-Hill Book Company.

Oberle, K. (1991). A decade in research in locus of control: What have we learned? Journal of Advance Nursing. 16, 800-805.

Pasero, C. \& McCaffery, M. (1993). Unconventional PCA: Making it Work for your Patient. American Journal of Nursing 93 (9), 38-41. 
Raatikainen, R. (1991). Dissatisfaction and insecurity of patients in domiciliary care. Journal of Advanced Nursing. 16. 154-164.

Richards D. A. \& Lambert, P. (1987). The nursing process: the effect on patients' satisfaction with nursing care. Journal of Advanced Nursing. 12. 559-562.

Rotter, J. (1975). Some problems and misconceptions related to the construct of internal versus external control of reinforcement. Journal of Consulting Clinical Psychologists. 43. 56-67.

Rubin, H., Ware, J., \& Hays, R. (1991). The PJHQ questionnaire: Exploratory Factor Analysis and Empirical Scale Construction. Medical Care, 28 (9), s22-s29.

Salazar, M. (1991). Comparison of Four Behavioral Theories. AAOH Journal. 39 (3), 128-135.

Schlenk, E. \& Hart, L. (1984). Relationship Between Health Locus of Control, Health Value, and Social Support and Compliance of Persons with Diabetes Mellitus. Diabetes Care. 7 (6), 566-574.

Shade, P. (1992). Patient-controlled analgesia: Can client education improve outcomes? Journal of Advanced Nursing, 17. 408-413.

Sokal, R. \& Rohlf, F. (1981). Biometry The Principles and

Practice of Statistics in Biological Research. (2nd ed.) New York: W.H. Freeman and Company. 588-591.

Speedling, E. \& Rose, D. (1985). Building an effective doctor-patient relationship: From patient satisfaction to patient participation. Social Science Medicine. 21, 115-120.

Steffen, G. (1988). Quality Medical Care A Definition. JAMA, 260 (1), 56-61. 
Tanner, C., Benner, P., Chesla, C., \& Gordon, D. (1993). The

Phenomenology of Knowing the Patient. Image Journal of Nursing Scholarship. 25 (4), 273-280.

Uustal, D. (1985). Values and Ethics in Nursing: From Theory to Practice. (3rd ed.) East Greenwich, Rhode Island: Educational Resources in Nursing \& Wholistic Health.

von Essen, L. \& Sjoden, P. (1993). Perceived Importance of Caring Behaviors to Swedish Psychiatric Inpatients and Staff, with comparisons to Somatically-III Samples. Research in Nursing \& Health, 16, 293-303.

Vuori, H. (1982). Quality Assurance of Health Services. Copenhagen: World Health Organization.

Wooldridge, P., Schmitt, M., Skipper, J., \& Leonard, R. (1983).

Behavioral Science and Nursing Theory. St. Louis: The C. V. Mosby Company. 
APPENDICES

84 


\section{APPENDIX I}

INITIAL INTERVIEW

( $70 \%$ of original size) 


\section{INITIAL INTERVIEW}

Now, I have some questions about employment.

Have you worked at a job for pay within the past year?

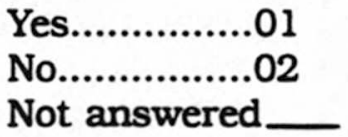

Are you CURRENTLY working at a job for pay?

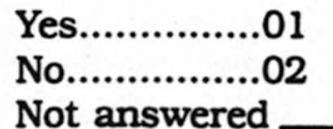

How many hours per week do you usually work?

Hours per week...

Not answered...

Not applicable.

We are trying to get some idea of the income range of people who come to The MED for care.

Last month, what was your PERSONAL income? (take-home)

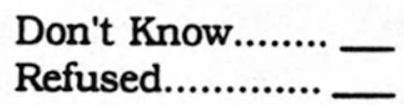

Last month, what was your combined HOUSEHOLD income? (take-home)

Don't know.

Refused. 
Name:

Study Number:

Unit:

Account Number:

Medical Record Number:

Admitting Diagnosis:

Admission Date:

1st Interview Date:

2nd Interview Date:

Discharge Date:

Marital/Partner Status: single=S married/together $=M$ separated $=\mathbf{X}$ widowed $=W$

Gender: male $=\mathbf{M}$ female $=F$

Race:

white $=\mathbf{W}$

black $=\quad B$

other $=0$ 
We are interested in knowing more about the kinds of people who come to The MED for care.

Before being in The MED this time, about how many times have you been admitted to a hospital?

What is your date of birth?

$$
\overline{\text { month }} \overline{\text { day }}-\overline{\text { year }}
$$

What is the highest grade or year you finished in school?

No schooling .00

Not Answered. (1)

What is your religious preference?

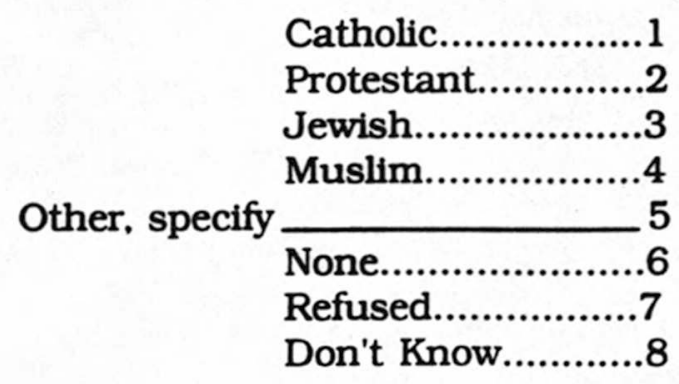




\section{INITLAL INTERVIEW}

I have some questions which you will answer by placing a mark on a line. Here is an example of the line.

Not At All

A Whole Lot

For example, if I ask you "how much is religion a source of strength and comfort to you", and you don't think religion is a source of much strength and comfort, you would place a mark near the lower left end of the line.

How much is religion a source of strength and comfort to you?

Not At All

A Whole Lot 


\section{INITLAL INTERVIEW}

Now, I have some questions about your health and why you are in The MED.

What is your biggest health problem that caused you to be in The MED NOW?

How bad is your

(chief symptom)?

Not Bad

At All

Very Bad

How worried are you about this health problem?

Not Worried

Very Worried

At All 
People have different hopes or goals for how being in The MED will help them with their health.

Tell me about your FIRST hope or goal for being in The MED .

(If clarification needed: "For instance, you said your biggest

health problem was How do you hope being in The MED will help you with that problem?)

Tell me your SECOND hope or goal for being in The MED.

(If clarification needed: Do you have other health problems in addition to your biggest health problem? If YES, what are your hopes for how the MED can help you with those?)

Tell me your THIRD hope or goal for being in The MED. 


\section{APPENDIX II \\ EXIT INTERVIEW \\ ( $70 \%$ of original size)}




\section{EXIT INTERVIEW}

\section{PGA}

People have different hopes or goals for how being in the MED will help them with their health. When I first talked with you, you told me your goals for being here at the MED. I am going to remind you of each of those goals. Then, I am going to ask you how much each goal has been met. Your goal can be met all the way, not at all, or somewhere in between.

I will ask you to answer by marking a place along a line like this to show about how much each goal was met:

Not At All All The Way

PGA

1. Your FIRST goal was:

This goal was met:

Not At All

All The

Way 
PGA

2. Your SECOND goal was:

This goal was met:

Not At All

All The

Way

3. Your THIRD goal was:

This goal was met:

Not At All

All The

Way 


\section{EXIT INTERVIEW}

About how much of the time were you in pain while you were here?

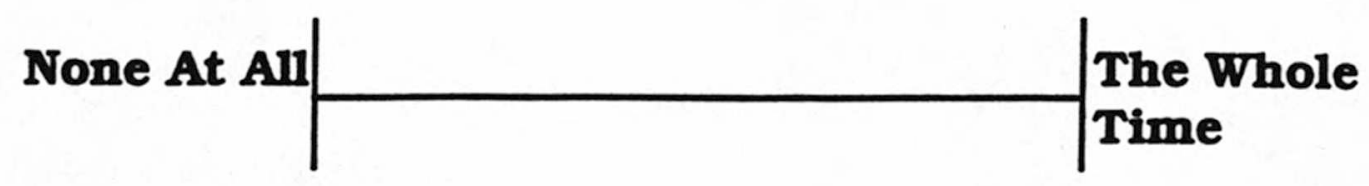

About how much pain did you have?

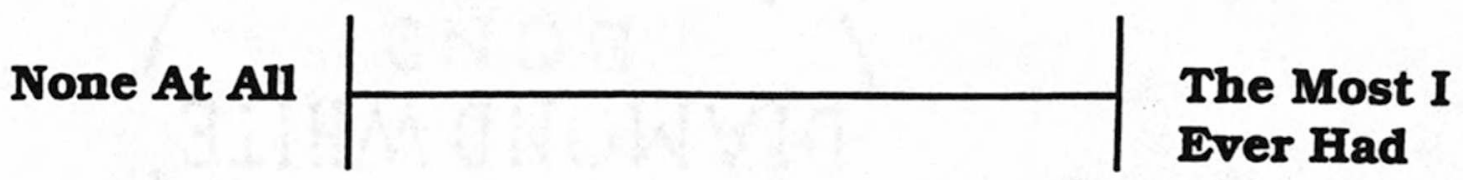

About how much pain are you in RIGHT now?

None At All

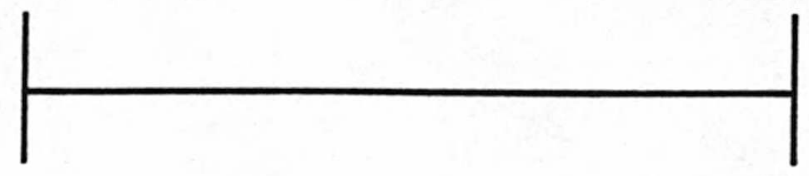

The Most I

Ever Had 


\section{EXIT INTERVIEW}

\section{QUALITY}

NOW, I would like to talk with you about the nursing care you received while you were here this time.

I will read you several statements. After each one, I would like for you to tell me how poor or how good you think the nurses did.

I will ask you to answer by marking a place along a line like this to show about how good or how poor you think your NURSING care was:

Very Poor Very Good

\section{PPQ-G}

Overall, how good was the nursing care you received?

Very Poor

Very Good 


\section{EXIT INTERVIEW}

\section{QUALITY}

Quality is a word people use to describe how good or how poor something is. We say something has good quality or it has poor (bad) quality.

When you think of good quality in nursing care, what does that mean to you?

Other Comments: 


\section{EXIT INTERVIEW}

\section{PPQ-S}

1. The nursing staff were willing to work with you to meet your needs. (How poor or how good did they do?)

Very Poor

Very Good

2. The nursing staff worked well with each other to take care of you. ( How poor or how good did they do?)

Very Poor

Very Good

3. The nursing staff helped you feel comfortable or relaxed. (How poor or how good did they do?)

Very Poor

Very Good 


\section{EXIT INTERVIEW}

\section{PPQ-S}

4. Your nurses did a good job giving you care with things like giving you medicine and doing IVs. (How poor or how good did they do?)

Very Poor Very Good

5. The nurses checked on how you were doing often enough. (How poor or how good did they do?)

Very Poor Very Good

6. Your nurses were quick to help you when you called. (How poor or how good did they do?)

Very Poor Very Good 


\section{EXIT INTERVIEW}

\section{PPO-S}

7. Your nurses were polite, kindly, and friendly with you. (How poor or how good did they do?)

Very Poor Very Good

8. Your nurses did a good job of sharing facts about your illness with you, your family, and your doctor. (How poor or how good did they do?)

Very Poor

Very Good 
APPENDIX III

COPYRIGHT PERMISSION REQUEST

( $85 \%$ of original size) 
Dr. June H. Larrabee

Assistant Professor

University of Tennessee, Memphis

College of Nursing

Dear Dr. Larrabee:

I am writing to request your permission to utilize the following from your dissertation, "Hospital Patients and Nurses Perceptions of Quality":

1. Larrabee's Model of Quality - the figure.

2. Larrabee's definition of quality, value, and beneficence.

3. The interview form (Appendix 1).

4. The exit interview form (Appendix 2).

5. The patient descriptive statistics.

6. The portion of the table describing quality variables.

All six of the above will be used, without addition or

changes, in my thesis. Please send me a copyright permission

letter to the address below.

Thank you for your assistance in this matter. I look forward to your response.

Sincerely,

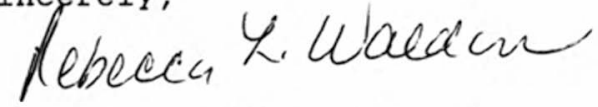

Rebecca L. Waldon, RN, BSN

454 N. McNeil

Memphis, Tennessee 38112

MSN Student 
APPENDIX IV

COPYRIGHT PERMISSION RESPONSE

( $85 \%$ of original size) 
Rebecca L. Waldon, RN, BSN

454 N. McNeil

Memphis, TN 38112

Dear Ms. Waldon:

You have my permission to use the copyrighted information, listed in your January 2, 1994 letter, which is taken from my dissertation "Hospital

Patients' and Nurses' Perceptions of Quality," and use in your thesis, as you have described. You must acknowledge within your thesis the original source of that copyrighted information .

Sincerely,

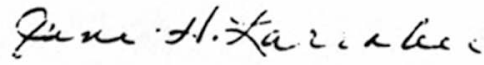

June H. Larrabee, Ph.D., R.N.

Assistant Professor 


\section{APPENDIX V}

INSTITUTIONAL REVIEW BOARD APPROVAL

( $85 \%$ of original size) 
Rebecca Waldon

Graduate Nursing

College of Nursing

UT Memphis

Dear Ms. Waldon:

On April 6, 1994 the UT Memphis Administrative Section of the Institutional Review Board reviewed your application entitled "Patient Perceptions of Quality: The Influence of Value and Beneficence" (IRB \# 5103) which included human subjects and/or tissue for investigative purposes.

The administrative section of the IRB determined your application to fall under the guidelines of exempt review, therefore, your application was approved in this regard as complying with proper consideration of the rights and welfare of human subjects, the risk involved and the potential benefits of the study.

Any further alterations in the protocol must be promptly reported and approved by the Institutional Review Board.

\author{
Sincerely yours,

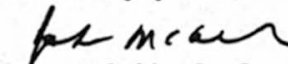




\section{VITA}

Rebecca Holliday Waldon received an Associate of Applied Science degree, Summa Cum Laude, from Shelby State Community College in 1984. She received a Bachelor of Science in Nursing degree, with honors, from the University of Tennessee at Memphis in 1992. She has been involved in direct patient care, unit management, quality assurance and community outreach during her nursing career. She has been involved locally and nationally in the care of burn patients by presenting at American Burn Association Conventions, and as a national instructor for the Advanced Burn Life Support classes.

Ms. Waldon is a member of the American Nurses Association, the American Burn Association and Sigma Theta Tau, Beta Theta Chapter-at-Large. Ms. Waldon received the Community Service Manager of the year award for outstanding service to the Memphis community from the Regional Medical Center, Memphis in 1989.

Ms. Waldon entered the Masters of Science in Nursing program at the University of Tennessee, Memphis in 1992. 